\title{
Padrão de especialização e competitividade internacional dos BRICS: 1985-2012
}

\author{
Ricardo Schmidt Filho* \\ Bianca Guaracy Carvalho da Cruz Lima**
}

\begin{abstract}
Resumo: Este trabalho procurou analisar o padrão de especialização e de competitividade das exportações dos BRICS durante o período 1985-2012. A análise foi feita sob a perspectiva schumpeteriana, relacionada ao grau de tecnologia e sob a perspectiva keynesiana, de acordo com o perfil da demanda. Foram utilizadas as taxonomias de Pavitt (1984) e Lall e Albaladejo (2001) e a matriz de competitividade criada pela CEPAL. Os resultados mostram que o BRICS é muito heterogêneo quanto ao perfil de inserção internacional, qualitativa e quantitativamente, com exceção da China, em se tratando do padrão produtivo, ainda não podem ser comparados às potencias mundiais.
\end{abstract}

Palavras-chave: BRICS. Estrutura produtiva. Comércio internacional.

\section{Specialization pattern and international competitiveness of the BRICS: 1985-2012}

\begin{abstract}
This paper aimed to analyze the specialization pattern and the exportations competitiveness of the BRICS during the period 1985-2012. The analysis was done under the Schumpeterian perspective, related to the technology rate and under the Keynesian perspective, according to the demand profile. It was used the taxonomies of Pavitt (1984) and Lall and Albaladejo (2001) and the competitiveness matrix created by the ECLAC. The results show that the BRICS are very heterogeneous, in relation to their international insertion, qualitatively and quantitatively, except by China, concerning to the production pattern, can't already be compared with the world powers.
\end{abstract}

Keywords: BRICS. Production structure. International trade.

Classificação JEL: E61. E23. F10.

\section{Introdução}

O desempenho dos indicadores macroeconômicos dos países representantes dos BRICS (Brasil, Rússia, Índia, China e África do Sul) alçou o grupo à categoria de novo centro dinâmico da Economia mundial, conferindo-lhe uma crescente representatividade internacional. Esses países abrangem uma extensa área territorial e, juntos, possuem cerca de $43 \%$ da população mundial, que, por sua vez, representa um grande e poderoso mercado consumidor, além de possuírem grandes quantidades de recursos minerais, hídricos e energéticos (ZUCOLOTO; CASSIOLATO, 2007).

As mudanças estruturais realizadas nos países do grupo a partir da década de 1990 foram determinantes para a guinada na Economia dos BRICS; na década de 1980, o Brasil vivia a “década

\footnotetext{
* Professor Doutor do Departamento de Economia da Universidade Federal de Campina Grande. E-mail: rschmidtfilho@hotmail.com

** Graduanda em economia na Universidade Federal de Campina Grande. E-mail: biancaguaracy@ hotmail.com.
} 
perdida", a Rússia ainda fazia parte da URSS em um regime socialista, a Índia engatinhava na busca pelo comércio externo e a China iniciava seu processo de reforma econômica (DE VIZIA; COSTA, 2010). Além disso, a África do Sul vivia sob o regime do apartheid e com todas as suas implicações internas e externas.

Nesse contexto, a abertura econômica foi de grande relevância, não só para a entrada de investimentos diretos externos e o aumento das importações, como também para o aumento das exportações e a internacionalização das empresas desses países, dando maior dinamismo a suas economias e contribuindo para o estágio atual dos BRICS. Para Baumann, Araújo e Ferreira (2010, p. 09) “[...] é esperável que um país exitoso no conjunto dos BRICs ${ }^{1}$ deva ter capacidade produtiva ampla (agrícola, industrial e de serviços) que corresponda o seu potencial econômico, apresente Economia relativamente estável e perfil não muito baixo no cenário internacional".

No entanto, apesar de possuírem certa diversidade na produção, notadamente, no que tange ao processo de inserção no comércio internacional, os países dos BRICS apresentam um padrão de especialização divergente. Por apresentarem abundância em recursos naturais, Brasil, Rússia e África do Sul são mais competitivos em setores com esse tipo de especialização; já Índia e China se especializaram em setores com produção intensiva em trabalho devido à vasta população presente nesses países.

Portanto, é importante analisar como evoluiu e como se comporta o processo de especialização em cada país e, ainda, se a especialidade de cada um contribui para a sua competitividade na inserção internacional, por meio da eficiência keynesiana, ou seja, em setores com demanda crescente e na eficiência schumpeteriana, no crescimento em setores de alta tecnologia, além de avaliar quais as perspectivas para os BRICS nesse contexto.

Desse modo, o objetivo central deste trabalho é analisar o padrão de especialização e de competitividade das exportações dos BRICS durante o período 1985-2012. Além desta introdução, o texto está dividido em outras quatro seções. A primeira faz a fundamentação teórica com a contextualização dos BRICS e uma revisão bibliográfica sobre a importância do conteúdo tecnológico para as exportações; a segunda apresenta a metodologia aplicada no estudo, seguida pelos resultados e discussões e, finalizando, são apresentadas as conclusões.

\footnotetext{
${ }^{1}$ Como a África do Sul só entrou formalmente para o grupo em 2011, alguns dados e citações farão referência somente a Brasil, Rússia, Índia e China, sendo denominados BRICs.
} 


\section{Caracterização e importância dos BRICS na Economia mundial}

A retomada da doutrina neoliberal a partir dos anos 1980, nos países desenvolvidos, e da década de 1990 nos demais países, determinou uma nova dinâmica na Economia mundial, com maior abertura econômica de vários países, entre outros fatores, em decorrência da contínua necessidade de criação de novos mercados para a expansão dos investimentos e do consumo. Nesse sentido, as empresas de investimentos denominaram como países emergentes aqueles que estavam emergindo da crise da dívida da década de 1980, em especial os latino-americanos, que passaram a representar boas perspectivas de lucro para o mercado e, desde então, esses países vêm ganhando certa importância no cenário mundial (KREGEL, 2009).

No início do milênio, quatro países desse grupo se destacaram pelas boas perspectivas que apresentavam para o futuro da Economia mundial: Brasil, Rússia, Índia e China, dando origem ao acrônimo BRICs. "Inicialmente os BRICs eram uma classe de Economia de mercado emergente de renda média, de um tamanho relativamente grande, com capacidade de expansão mais ou menos autossustentada" (KREGEL, 2009, p. 21).

No relatório em que o termo foi usado originalmente, O’Neill (2001) destacou a crescente importância dos quatro países, ao analisar seu Produto Interno Bruto baseado no Poder de Paridade de Compra (PPC), que, para o autor, é uma análise mais representativa de uma Economia. Em 2000 os BRICs representavam $8 \%$ do PIB mundial, mas esse número subia para 23,3\% quando baseado no PPC e projeções indicavam para 2011, 14,2\% e 27,0\%, respectivamente. Com base nesses dados, o autor defendeu a inclusão de Brasil, Rússia, Índia e China no G-7, uma vez que esses países se tornariam maiores que antigos membros, como Canadá e Itália e, por isso, suas políticas fiscais e monetárias passariam a interferir cada vez mais na Economia mundial, justificando sua inclusão no grupo, além de uma intensificação na (real) cooperação e integração da política e da Economia internacionais.

Posteriormente, Wilson e Purushothaman (2003) fizeram um estudo ainda mais profundo do grupo $^{2}$, com projeções para 2050 de dados relacionados não só ao tamanho e ao crescimento da Economia, como também à renda e à demografia, à demanda e aos movimentos cambiais. Os autores concluem que os BRICs, que em 2003 totalizavam apenas $15 \%$ do G-6 $6^{3}$, em 2025 passarão a ser 50\% e já em 2040 poderão ser maiores que o G-6 e que em 2050, desse grupo, somente Estados Unidos e Japão estarão entre as seis maiores Economia do mundo. No que tange à

\footnotetext{
${ }^{2}$ Este relatório já inclui um box sobre a África do Sul, considerando a importância do país como a principal economia do continente africano. Os autores destacam que apesar de o país não possuir o mesmo tamanho absoluto, as projeções para crescimento do PIB e do PIB per capita são compatíveis com os demais países do grupo.

${ }^{3} \mathrm{O}$ grupo inclui Alemanha, Estados Unidos, França, Itália, Japão e Reino Unido. O Canadá foi excluído, pois no período o seu PIB era menor que US\$ 1 trilhão. No entanto, os autores destacam que a inclusão de outros países não afetariam as conclusões do obtidas.
} 
demanda, Wilson e Purushman (2003) destacaram o impressionante crescimento da demanda dos países que compõem os BRICs; a projeção feita coloca que, em 2050, o crescimento da sua demanda será quatro vezes maior que no G-6. No entanto, vale ressaltar que mesmo superando o G6 no PIB e no crescimento da demanda, a população dos BRICs ainda será relativamente mais pobre, considerando o PIB per capita.

Wilson e Purushothaman (2003) abordam, principalmente, o destaque dos BRICs não só pelo seu tamanho e pela crescente importância na política internacional, como também apontou O’Neil (2001), mas como países que devem estar no foco do planejamento estratégico de longo prazo para firmas e investidores, devido aos resultados consistentes de suas Economias.

Para Kregel (2009) a expressão BRICs não foi criada por economistas, mas por instituições financeiras em resposta à crise provocada pela bolha do mercado de ações "ponto.com" e pelo atentado terrorista de 11 de setembro, que reuniram dados e projeções para formar o grupo não por similaridades econômicas e sociais, mas por se tratar de países que representavam um grande potencial de lucros no mercado financeiro e, especialmente, no mercado de equidades ${ }^{4}$. Segundo dados do Hang Seng China Enterprises Index, no período entre 2001 e 2007 esse mercado cresceu $369 \%$ no Brasil, $499 \%$ na Índia, 630\% na Rússia e $817 \%$ na China.

No entanto, os indicadores apresentados ao longo da década se comprovaram e, em alguns casos, foram superados e os BRICS deixaram de ser apenas uma expressão do mercado financeiro e se tornaram um grupo de crescente importância política e econômica no cenário mundial. O’Neill (2001) projetou que, em 2010, os BRICs responderiam por volta de 10\% do PIB mundial, mas já em 2007, esse número chegava a 15\%. Wilson e Purushothaman (2003) projetaram que a China só se tornaria a segunda Economia do mundo em 2016, no entanto em 2010, seis anos antes, o país superou o Japão e alcançou o posto.

De 2001 a 2007, o mundo viveu um período de forte crescimento econômico impulsionado especialmente por países emergentes como os BRICS. Em 2001, o Brasil teve crescimento de 1,3\% do PIB e 6,1\% em 2007, com média de 3,4\% para o período, a Rússia cresceu 5,1\% em 2001 e 8,5\% em 2007 e média de 6,8\%, a Índia em 2001 cresceu 4,9\%, em 2007 9,8\% e obteve média de 7,6\%, já a China em 2001 cresceu 8,3\%, em 2007 14,2\%, com média de 10,8\% e a África do Sul cresceu 2,7\% em 2001, 5,5\% em 2007 e média de 4,3\%. Além disso, de acordo com o Instituto de Pesquisa Econômica Aplicada (IPEA, 2011) no período 2008-2009, após a grave crise econômica, o grupo foi responsável por $2 / 3$ do crescimento da demanda da Economia mundial (renda nacional bruta em termos de paridade poder de compra).

\footnotetext{
${ }^{4}$ Mais conhecido como mercado de ações.
} 
Nesse contexto, já em 23 de setembro de 2006, em uma Reunião de Chanceleres organizada à margem da $61^{\mathrm{a}}$ Assembleia Geral das Nações Unidas, Brasil, Rússia, Índia e China passaram a adotar um mecanismo de articulação conjunta na política internacional. Desde então, os quatro países realizaram várias reuniões para deliberar sobre assuntos de interesse comum, o que aumenta cada vez mais o grau de institucionalização do grupo, mesmo que esse ainda seja um agrupamento informal que existe apenas pela vontade política dos países. E em 2011 a África do Sul foi incorporada ao grupo, tornando-se BRICS. (MINISTÉRIO DAS RELAÇÕES EXTERIORES, 2013).

No entanto, Deagaut (2013) destaca que, após a crise de 2008, quando o poder do grupo foi colocado à prova e foi necessária a articulação entre seus membros para a proposta de soluções para a crise, pouco ou nada foi feito, ao contrário revelou-se toda a fragilidade do grupo, que sofreu fortes impactos em suas economias. E, além disso, ficaram ainda mais evidentes as divergências internas entre os países, que, em geral, atuam mais como competidores do que aliados na política internacional.

\section{Comércio Internacional nos BRICS}

Grande parte do crescimento econômico e, consequentemente, da importância no cenário mundial dos BRICS se deve ao processo de abertura econômica realizada pelos países, especialmente a partir da década de 1990, que viabilizou não só o crescimento das importações e do investimento direto estrangeiro, como também as exportações e a internacionalização de empresas locais.

Mesmo se tratando de países com uma população grande e crescente aumento da demanda interna, o volume de exportações dos BRICS cresceu bastante a partir de meados da década de 1990, o que enfatiza a possibilidade de obter "exportações viabilizadas pelo crescimento" ao invés de um "crescimento liderado pelas exportações" e, com isso, maior espaço nas relações internacionais, como destacam Baumann, Araújo e Ferreira (2010).

Segundo o IPEA (2010), apesar de toda a corrente global ter expandido no período de 1996 a 2008 e ter praticamente dobrado, aumento das exportações dos BRICs não foi apenas um reflexo desse contexto, uma vez que as taxas de crescimento do grupo foram ainda mais elevadas. $\mathrm{O}$ destaque no crescimento se dá, especialmente, a partir de 2002. A seguir, a Tabela 1 apresenta os valores absolutos das exportações de cada um dos países no período de 2002 a 2008. 
Tabela 1: Exportações por país 2002-2011 (US\$ bilhões)

\begin{tabular}{c|c|c|c|c|c|c}
\hline Anos & Brasil & China & Índia & Rússia & A. do Sul & Total \\
\hline 2002 & 60 & 326 & 51 & 107 & 30 & $\mathbf{5 7 4}$ \\
2003 & 73 & 438 & 61 & 131 & 36 & $\mathbf{7 3 9}$ \\
2004 & 97 & 594 & 75 & 166 & 46 & $\mathbf{9 7 8}$ \\
2005 & 119 & 763 & 98 & 239 & 52 & $\mathbf{1 . 2 7 1}$ \\
2006 & 138 & 970 & 121 & 292 & 52 & $\mathbf{1 . 5 7 3}$ \\
2007 & 161 & 1.219 & 154 & 353 & 63 & $\mathbf{1 . 9 5 0}$ \\
2008 & 198 & 1.429 & 178 & 460 & 73 & $\mathbf{2 . 3 3 8}$ \\
2009 & 153 & 1.203 & 165 & 285 & 54 & $\mathbf{1 . 8 6 0}$ \\
2010 & 202 & 1.580 & 223 & 374 & 79 & $\mathbf{2 . 4 5 8}$ \\
2011 & 256 & 1.901 & 295 & 496 & 93 & $\mathbf{3 . 0 4 1}$ \\
\hline
\end{tabular}

Fonte: Ministério das Relações Exteriores (2012)

As exportações do Brasil cresceram 326,67\%, as da China 483,13\%, na Índia o crescimento foi de 478,43\%, na Rússia de 363,55\% e na África do Sul 210\%; já no grupo como um todo, as exportações cresceram 429,79\%, demonstrando o aumento da importância dos BRICS no mercado internacional, assim como o crescimento da importância das exportações para o dinamismo da Economia dos países membros do grupo. No entanto, vale ressaltar que esse período foi marcado pelo boom de commodities, que foi interrompido exatamente a partir de 2008, em decorrência dos efeitos da crise, como pode ser demonstrado pela queda das exportações em 2009, no entanto, já em 2010 os países retomaram o crescimento das exportações.

Contudo, como foi abordado anteriormente, uma característica marcante do grupo é a diferença entre seus países, que, nesse contexto, se reflete não só no volume exportado (Tabela 1), como também no padrão de especialização comercial de Brasil, Rússia, Índia, China e África do Sul.

O comunicado do IPEA (2010) aponta que o Brasil se destaca no comércio internacional de produtos primários agropecuários, a Rússia nos produtos primários minerais (basicamente do petróleo), a Índia apresenta vantagens em produtos intensivos em recursos naturais, além dos produtos intensivos em trabalho, sendo estes também os de maior competitividade da China. A África do Sul também se destaca na produção de produtos primários minerais, como ouro, diamante e carvão.

\section{Comércio internacional, inovação e desenvolvimento econômico}

A teoria econômica tradicional, baseada no modelo ricardiano das vantagens comparativas, defende que um país, ao especializar sua produção em bens nos quais é relativamente mais competitivo, alcançaria maior produtividade e maior bem-estar social. Na mesma linha teórica, o modelo de Heckscher-Ohlin aponta que, considerando um conjunto de preços relativos internacionais, cada país irá se especializar na produção em setores mais intensivos em fatores de produção nos quais é mais abundante, assumindo que a tecnologia entre os países é a mesma, as 
curvas de indiferença são similares e a mobilidade dos fatores de produção entre os setores é flexível. (SCHMIDT FILHO, 2011).

No entanto, essa teoria não se comprovou empiricamente não só no âmbito do perfil dos fluxos de comércio internacional, como apontam Dosi, Pavitt e Soete (1990), uma vez que o fluxo de comércio entre países com composições fatoriais semelhantes é muito mais intenso do que entre países com composições diferentes, contrariando a lógica do modelo ricardiano, como também pelo fato de a especialização no comércio internacional não haver trazido maior produtividade e bemestar para todos os países.

Uma das correntes teóricas que refuta com veemência essa linha de pensamento é a escola cepalina fundamentada no pensamento de Prebisch, que utiliza o comércio internacional para explicar o subdesenvolvimento dos países, em especial na América Latina. Para o autor a lógica ricardiana funcionava somente entre países com estrutura produtiva, econômica e social parecidas.

A falha dessa premissa consiste em ela atribuir um caráter geral aquilo que, em si mesmo, é muito circunscrito. Se por coletividade entende-se tão somente o conjunto dos grandes países industrializados, é verdade que o progresso técnico distribui-se gradativamente entre todos os grupos e classes sociais. Todavia, se o conceito de coletividade também é estendido à periferia da Economia mundial, essa generalização passa a carregar em si um grave erro. Os imensos benefícios do desenvolvimento da produtividade não chegaram à periferia numa medida comparável àquela de que logrou desfrutar a população desses grandes países. Daí as acentuadíssimas diferenças do padrão de vida das massas destes e daquela (PREBISCH, 2000, p. 72).

De acordo com o autor, os países periféricos transferiam parte dos frutos de seu progresso técnico para os países desenvolvidos, devido à deterioração dos termos de troca no comércio entre os países, pois a taxa de crescimento da produtividade dos produtos manufaturados é maior que nos produtos primários, mas os preços não caíam em decorrência desse aumento de produtividade. Assim, "a incapacidade da periferia para reter totalmente os lucros gerados por seu próprio desenvolvimento, os frutos do seu progresso técnico, [...] contribui para concentrar nos centros as rendas geradas pelo conjunto do sistema" (GURRIERI, 1982, p, 18).

Corroborando com essa ideia Dosi, Pavitt e Soette (1990) argumentam que a "eficiência ricardiana" não necessariamente conduz ao melhor resultado para a Economia, uma vez que os setores apresentam diferenças no "potencial dinâmico" (em termos de economias de escala, progresso técnico, possibilidades de divisão de trabalho, learning-by-doing, learning by using, etc.) levando a diferentes trajetórias tecnológicas.

Nesse contexto, a inovação tecnológica se apresenta como o fator capaz de fornecer o dinamismo necessário às economias que pretendem garantir uma posição de vantagem no comércio internacional. Para Parente e Prescott (2004) o nível de desenvolvimento entre os países industriais é alcançado por um país que consegue eliminar as limitações que apresenta quanto à utilização da 
tecnologia (HAUSMANN; HWANG; RODRIK, 2005; DOSI; PAVITT; SOETE, 1990; FAGERBERG; VERSPAGEN, 2007).

A importância do comércio internacional para o crescimento de uma Economia merece destaque, pois a lei de Thirlwall nos diz que: a taxa de crescimento econômico de longo prazo é determinada pela divisão da taxa de crescimento de longo prazo das exportações pela elasticidade de longo prazo da demanda por importações (THIRLWALL, 1979; MCCOMBIE; THIRLWALL, 1994). Outros autores apontam que existe uma relação entre desempenho tecnológico e crescimento exportador dos países e acrescentam que essa relação depende da capacidade de desenvolver o sistema de inovação por parte de um país. (LAURSEN; MELICIANI, 2000; MALERBA; MONTOBBIO, 2003; FAGERBERG; VERSPAGEN, 2007).

Assim, destacando que a inovação se dá por meio de um processo de aprendizagem histórico, Xavier (2000) argumenta que a diferença entre os países ocorre pelo fato de os países desenvolvidos participarem com produtos de maior conteúdo tecnológico, ou seja, maiores preços, maior penetração em mercados com maior capacidade de absorção de renda e os países em desenvolvimento com produtos com menor capacidade tecnológica, menores preços e menor capacidade de absorção de renda.

Sendo assim, constatada a importância tanto do crescimento do comércio internacional como também das inovações tecnológicas contidas nos produtos e nos processo produtivos da Economia de um país, a seguir apresenta-se a metodologia de estudo, a qual toma como base esses dois importantes aspectos para a análise do padrão de especialização internacional dos BRICS.

\section{Metodologia}

Quanto aos objetivos, a pesquisa é classificada como exploratória e descritiva, uma vez que utiliza os dados não só para demonstrar qual o perfil de inserção internacional dos BRICS como também para avaliar se ele é o mais adequado dentro da perspectiva de competitividade considerada mais eficaz no atual cenário da Economia mundial. E quanto aos procedimentos técnicos a pesquisa é bibliográfica, utilizando as bases de dados do Comtrade, Banco Mundial, Comissão Econômica para a América Latina (CEPAL) e da Organização Mundial do Comércio (OMC).

Primeiramente, os dados são analisados sob a perspectiva schumpeteriana e para tanto, os setores produtivos são agrupados de acordo com o seu perfil tecnológico e avaliados com base nos indicadores de comércio internacional. De acordo com essa perspectiva, os países mais competitivos devem apresentar resultados mais expressivos nos setores considerados intensivos em tecnologia. São utilizadas duas classificações setoriais, propostas por Pavitt (1984) e por Lall e Albaladejo (2001). 


\subsection{Classificação Setorial}

Na tipologia proposta por Pavitt (1984), os setores são padronizados de acordo com seu grau de tecnologia, considerando as fontes, a natureza e os impactos das inovações, "definidas pelas fontes de insumos de conhecimento, pelo tamanho e linhas principais de atividade das firmas inovadoras e pelos setores que produzem e são os principais usuários da inovação" (PAVITT, 1984, p. 01).

Tabela 2: Padrão setorial e tecnológico de Pavitt (1984)

\begin{tabular}{|c|c|c|c|c|c|}
\hline $\begin{array}{l}\text { Características } \\
\text { principais das } \\
\text { Categorias } \\
\end{array}$ & \multicolumn{5}{|c|}{ Categoria da Firma } \\
\hline & & & Intensiva em Prod & ç̧̃̃o & \\
\hline \multirow{2}{*}{\multicolumn{2}{|c|}{ Atividades Típicas }} & $\begin{array}{l}\text { Dominada Pelo } \\
\text { Fornecedor }\end{array}$ & $\begin{array}{l}\text { Intensiva em } \\
\text { escala }\end{array}$ & $\begin{array}{l}\text { Fornecedores } \\
\text { Especializados }\end{array}$ & Baseada em Ciência \\
\hline & & $\begin{array}{l}\text { Agricultura, } \\
\text { Const. Civil, } \\
\text { Serviços } \\
\text { privados, } \\
\text { manufatura } \\
\text { Tradicional. } \\
\end{array}$ & $\begin{array}{l}\text { Materiais } \\
\text { volumosos (aço, } \\
\text { vidro); Montagem } \\
\text { (Bens de consumo } \\
\text { Duráveis e autos) }\end{array}$ & $\begin{array}{l}\text { Maquinaria, } \\
\text { instrumentos de } \\
\text { precisão. }\end{array}$ & $\begin{array}{l}\text { Eletrônico/elétrico; } \\
\text { Químico. }\end{array}$ \\
\hline \multirow[t]{3}{*}{$\begin{array}{l}\text { Fatores } \\
\text { determinantes } \\
\text { das atividades } \\
\text { tecnológicas }\end{array}$} & $\begin{array}{ll}\text { Fontes } & \text { de } \\
\text { tecnologia } & \end{array}$ & $\begin{array}{lr}\text { Extensão } & \text { dos } \\
\text { serviços } & \text { de } \\
\text { pesquisa dos } \\
\text { fornecedores }\end{array}$ & $\begin{array}{lr}\begin{array}{l}\text { Engenharia } \\
\text { produção }\end{array} & \text { de } \\
\text { Fornecedores } & \end{array}$ & $\begin{array}{l}\text { Projeto e } \\
\text { desenvolviment } \\
\text { o pelo Usuário. }\end{array}$ & $\begin{array}{l}\text { P\&D; } \quad \text { Ciência } \\
\text { Pública; Engenharia } \\
\text { de produção. }\end{array}$ \\
\hline & $\begin{array}{ll}\text { Tipos } & \text { de } \\
\text { Usuários } & \\
\end{array}$ & $\begin{array}{ll}\begin{array}{l}\text { Sensível } \\
\text { preço }\end{array} & \text { ao } \\
\end{array}$ & Sensível ao preço & $\begin{array}{ll}\begin{array}{l}\text { Sensível ao } \\
\text { desempenho }\end{array} & \text { ao } \\
\end{array}$ & Misto. \\
\hline & $\begin{array}{l}\text { Mecanismos de } \\
\text { Apropriação }\end{array}$ & $\begin{array}{l}\text { Não-técnico } \\
\text { (marcas, } \\
\text { marketing, } \\
\text { propaganda, } \\
\text { aparência } \\
\text { estética). }\end{array}$ & $\begin{array}{l}\text { Segredo e Know- } \\
\text { how de processo; } \\
\text { defasagens } \\
\text { técnicas; Patentes; } \\
\text { economias } \\
\text { dinâmicas de } \\
\text { aprendizado. }\end{array}$ & $\begin{array}{l}\text { Know-how de } \\
\text { projeto; } \\
\text { Conhecimento } \\
\text { dos usuários; } \\
\text { patentes }\end{array}$ & $\begin{array}{lr}\text { Know-how de P\&D; } \\
\text { Patentes; segredo e } \\
\text { know-how } \\
\text { processo; economias } \\
\text { dinâmicas } \\
\text { aprendizador }\end{array}$ \\
\hline $\begin{array}{l}\text { Trajetórias } \\
\text { tecnológicas }\end{array}$ & & $\begin{array}{l}\text { Redução } \quad \text { de } \\
\text { custos }\end{array}$ & $\begin{array}{l}\text { Redução de custos } \\
\text { (no projeto do } \\
\text { produto). }\end{array}$ & $\begin{array}{ll}\text { Projeto } & \mathrm{de} \\
\text { produto } & \end{array}$ & Mista. \\
\hline \multirow[t]{4}{*}{$\begin{array}{l}\text { Características } \\
\text { mensuradas }\end{array}$} & $\begin{array}{ll}\begin{array}{l}\text { Fontes } \\
\text { tecnologia }\end{array} & \text { de } \\
\end{array}$ & Fornecedores & $\begin{array}{l}\text { Interna; } \\
\text { Fornecedores }\end{array}$ & Interna; Clientes & Interna; Fornecedores \\
\hline & $\begin{array}{l}\begin{array}{l}\text { Inovação } \\
\text { relativamente } \\
\text { predominante }\end{array} \\
\end{array}$ & Processo & Processo & Produto & Mista \\
\hline & $\begin{array}{l}\text { Tamanho } \\
\text { relativo das } \\
\text { firmas } \\
\text { inovadoras } \\
\end{array}$ & Pequeno & Grande & Pequeno & Grande \\
\hline & $\begin{array}{l}\text { Intensidade e } \\
\text { direção da } \\
\text { diversificação } \\
\text { tecnológica }\end{array}$ & Baixa; Vertical & Alta; Vertical. & $\begin{array}{l}\text { Baixa; } \\
\text { Concêntrica. }\end{array}$ & $\begin{array}{l}\text { Baixa, Vertical/ Alta, } \\
\text { concêntrica. }\end{array}$ \\
\hline
\end{tabular}

Fonte: Pavitt (1984)

Tendo como referência a firma, Pavitt (1984) conclui que a mudança tecnológica é um processo cumulativo, ou seja, a capacidade de inovação tecnológica do futuro está condicionada ao que foi realizado no passado. As trajetórias das firmas podem ser explicadas por diferenças setoriais em três categorias: 1) fontes tecnológicas (P\&D próprio ou contratado, usuários), 2) as necessidades 
dos usuários (preços, desempenho, confiabilidade) e 3) os meios de apropriação de lucros derivados do sucesso inovador (segredo industrial, patentes). Além disso, o autor também diferencia os setores "quanto à importância relativa das inovações de produto e de processo ${ }^{5}$, quanto às fontes de tecnologia de processo e quanto ao tamanho e padrão de diversificação tecnológica das firmas inovadoras" (PAVITT, 1984, p. 13).

A partir desses critérios, o autor classifica as indústrias em três grandes grupos: 1) dominados por fornecedores (supplier dominated), 2) setores intensivos em produção (production intensive) e 3) setores baseados em ciência (science based). (Tabela 2).

Nas firmas dominadas pelos fornecedores, como o próprio nome indica, a maioria das inovações tecnológicas é dependente das máquinas e de equipamentos comprados dos fornecedores, sendo, portanto, em sua maioria, inovações de processo. O ganho de competitividade dessas firmas advém da redução de custos, da qualificação do pessoal e desenvolvimento da estética, da marca e da propaganda, com pouca possibilidade de ênfase em P\&D. Os setores que compõem esse grupo são os de produção industrial mais tradicional, como o têxtil e o de calçados, além da agricultura, construção civil, entre outros.

Os setores intensivos em produção são caracterizados por adquirir qualificações tecnológicas a fim de obter economias de escala, uma vez que os usuários de seus produtos são sensíveis ao preço e, por consequência, esses setores são geralmente compostos por firmas de grande porte. As inovações são tanto de processo como de produto. Seus departamentos de P\&D são bem desenvolvidos, no entanto as inovações são também apropriadas de fornecedores de grande porte, assim como de pequenos fornecedores especializados. As principais indústrias desse grupo são a metalúrgica, de cimento, construção naval, bens duráveis, automóveis, entre outros.

Os setores baseados em ciência possuem alta base/oportunidade tecnológica obtida especialmente em seus próprios departamentos de P\&D em constante interação com as universidades e outros estabelecimentos de $\mathrm{P} \& \mathrm{D}$. $\mathrm{O}$ grupo se divide em Fornecedores especializados, Intensivos em escala e Intensivos em tecnologia, suas principais indústrias são a química e eletro/eletrônica.

Com o intuito de operacionalizar a classificação de Pavitt (1984) às bases de dados disponíveis, Laplane et al. (2001) desenvolveram um "tradutor" que divide os setores em seis novos grupos: 1) Produtos primários; 2) Indústria intensiva em recursos naturais; 3) Indústria intensiva em trabalho (ou tradicionais); 4) Indústria intensiva em escala; 5) Fornecedores especializados e 6) Indústria intensiva em P\&D. Esse "tradutor" agrega 258 grupos setoriais em âmbito de três dígitos

\footnotetext{
5 "Definimos inovações de produto como as que são usadas fora dos setores que as produziram e inovações de processo como aquelas que são usadas dentro desses setores" (PAVITT, 1984, p. 07).
} 
na classificação SITC (Standard International Trade Classification) da Organização das Nações Unidas (ONU) em subgrupos para as exportações mundiais. (Tabela 3).

Tabela 3: Classificação setorial de acordo com a tipologia de Pavitt (1984) e tradutor de Laplane et al. (2001)

\begin{tabular}{|c|c|c|}
\hline $\begin{array}{l}\text { CLASSIFICAÇÃO } \\
\text { PAVITT (1984) }\end{array}$ & $\begin{array}{l}\text { GRUPOS LAPLANE } \text { et al. } \\
\text { (2001) }\end{array}$ & TRADUTOR LAPLANE et al. (2001) \\
\hline \multirow{8}{*}{$\begin{array}{l}\text { Dominados } \quad \text { pelos } \\
\text { Fornecedores }\end{array}$} & \multirow[t]{3}{*}{ Produtos Primários } & Produtos Primários Agrícolas \\
\hline & & $\begin{array}{l}\text { Produtos Primários } \\
\text { Minerais }\end{array}$ \\
\hline & & Produtos Primários Energéticos \\
\hline & \multirow[t]{4}{*}{ Intensivas em recursos naturais } & Indústria Agroalimentar \\
\hline & & $\begin{array}{l}\text { Indústria Intensiva em outros recursos } \\
\text { agrícolas }\end{array}$ \\
\hline & & Indústria intensiva em recursos Minerais \\
\hline & & $\begin{array}{llll}\begin{array}{l}\text { Indústria intensiva em } \\
\text { energéticos }\end{array} & \text { recursos } \\
\end{array}$ \\
\hline & Indústria intensiva em trabalho & Indústria intensiva em trabalho \\
\hline \multirow[t]{2}{*}{ Intensivos em Produção } & Indústria intensiva em Escala & Indústria intensiva em Escala \\
\hline & Fornecedores Especializados & Fornecedores Especializados \\
\hline Intensivas em Ciência & Indústria intensiva em P\&D & Indústria intensiva em P\&D \\
\hline
\end{tabular}

Fonte: Elaboração própria a partir de PAVITT (1984) e LAPLANE et al. (2001)

Essa tipologia adota uma perspectiva dinâmica agrupando os setores de acordo com os processos inovadores, ou seja, se há apropriação externa ou se a inovação é produzida internamente, apontando o segundo caso como mais importante para a produtividade da Economia, pois considera que a inovação é fruto de um aprendizado adquirido com a rotina do processo produtivo. No entanto, a outra classificação setorial adotada, proposta por Lall e Albaladejo (2001), ordena os setores de acordo com sua intensidade tecnológica e é uma classificação mais estática, que classifica os setores segundo o conteúdo tecnológico do produto produzido, mas, na qual o processo de produção não possui grande relevância. A classificação segue a seguinte ordenação (em ordem crescente):

1 Produtos Primários (PP)

2 Baseados em recursos naturais

2.1) Agro-Baseados (RB1)

2.2) Outros (RB2)

3 Manufaturas de baixa tecnologia

3.1) Têxtil, vestuário e calçados (LT1)

3.2) Outros produtos (LT2)

4 Manufaturas de média tecnologia

4.1) Automotivo (MT1)

4.2) Processo (MT2) 


\section{3) Engenharia (MT3)}

5 Manufaturas de alta tecnologia

5.1) Eletrônicos e Elétrico (AT1)

\section{2) Outros (AT2)}

Nesse sentido, por meio das classificações supracitadas são medidos os graus de inovação e tecnologia dos setores exportadores dos países dos BRICS com base em sua evolução durante o período pesquisado, como também são avaliadas as semelhanças e/ou divergências em sua trajetória de inserção comercial.

\subsection{Indicadores de desempenho exportador}

A análise do desempenho exportador tem como objetivo fazer a avaliação sob a perspectiva keynesiana, ou seja, considera mais competitivos os setores nos quais há o aumento da demanda durante o período adotado, independentemente dos aspectos inovadores e/ou tecnológicos. E é feita por intermédio da Análise de Competitividade dos Países (Competitive Analisys of Nations - CAN), um programa elaborado pela CEPAL com uma base de dados que permite avaliar o dinamismo das exportações mundiais, assim como a participação de cada país no cenário internacional, sendo possível verificar em quais setores um país ganha ou perde participação de mercado e em quais setores ocorre especialização das exportações.

A competitividade geral de um país é dada pela sua participação em mercados mais dinâmicos, ou seja, nos quais o volume de exportações é crescente e a elevada proporção de sua participação em um mercado específico (especialização das exportações).

A ferramenta CAN da CEPAL leva em consideração dois aspectos para avaliar a competitividade das exportações: 1) A participação de mercado e a mudança ocorrida nesta de um determinado setor (ou grupo de setores) em relação a um mercado importador específico (por exemplo, as exportações mundiais como um todo) e 2) A mudança relativa das importações desse setor em relação ao mercado internacional considerado, ou seja, se o setor ganha ou perde importância relativamente a outros setores, ou ainda, se o setor cresce mais ou menos do que a média de crescimento das importações.

Uma forma de visualizar e determinar a competitividade dos países é a utilização da matriz de competitividade (Figura. 1). A forma de análise será a mesma adotada por Madeng (1991). 


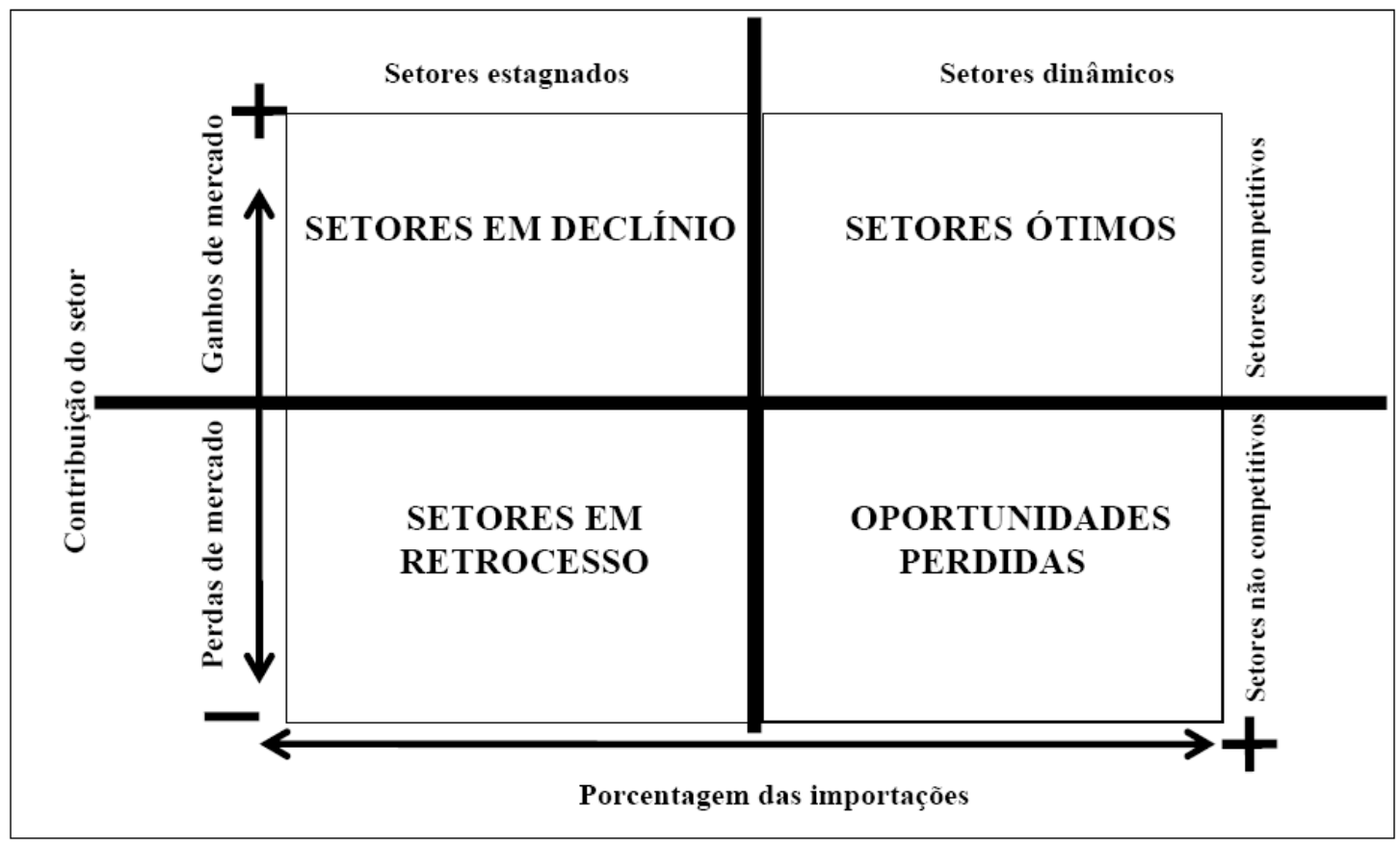

Figura 1: Matriz de competitividade

Fonte: Madeng (1991)

O eixo vertical trata da dinâmica externa, ou seja, o ritmo de expansão das exportações mundiais. O lado direito representa os setores dinâmicos que são aqueles cuja demanda mundial cresceu mais que a média mundial e o no lado esquerdo estão os setores estagnados, nos quais o crescimento da demanda foi menor que a média mundial. $\mathrm{O}$ eixo horizontal analisa a dinâmica interna das exportações. Acima do eixo estão os setores nos quais o país está ganhando participação no mercado mundial e abaixo do eixo estão os setores nos quais o país perde participação no mercado internacional. A junção dos dois eixos forma quatro quadrantes: 1) Setores ótimos; 2) Setores em declínio; 3) Oportunidades perdidas; e 4) Setores em retrocesso.

Os setores ótimos são aqueles em que o país tem crescente participação de mercado (market share) e ao mesmo tempo há a crescente expansão das exportações no mercado externo. Os setores em declínio são os que perdem dinamismo no mercado internacional, mas nos quais o país apresenta ganho de market share. Oportunidades perdidas representam os setores com dinâmica internacional e que, no entanto, o país perde participação de mercado. E os setores em retrocesso são os que ao mesmo tempo perdem dinamismo externo e em que o país perde market share.

A matriz de competitividade permite analisar a dinâmica das exportações por meio da oferta, ou seja, da estrutura produtiva local e da capacidade de atender a demanda, sendo essa a outra vertente analisada, que representa o mercado importador e as suas preferências. Assim, a inserção competitiva de um país deve estar concentrada nos setores dinâmicos, em especial nos setores ótimos. 
Adicionalmente, são adotados indicadores de comércio internacional com o intuito de melhor avaliar e compreender a evolução dos padrões de inserção dos BRICS, tanto sob o aspecto do desempenho internacional como também o da participação e da contribuição interna dos setores exportadores.

\subsection{Indicadores de comércio internacional}

A pesquisa utiliza três indicadores de comércio internacional: Market Share; Vantagem Comparativa Revelada; e Contribuição ao Saldo.

O market share (MS) setorial apresenta a quantidade de exportações de um grupo setorial $(i)$ de um país $(j)$ em relação à quantidade total de exportações mundiais do grupo setorial, ou seja, o indicador mede a parcela de mercado de exportações de um país em um determinado setor.

O indicador é calculado pela seguinte fórmula:

$$
M S=\frac{X_{i j}}{X_{i}}
$$

Onde:

$\mathrm{X}_{\mathrm{ij}}=$ exportações do grupo setorial i pelo país $\mathrm{j}$

$\mathrm{X}_{\mathrm{i}}=$ exportações do grupo setorial i no mundo

A Vantagem Comparativa Revelada (VCR) indica se um país possui ou não vantagens comparativas em um determinado setor. Se o indicador for maior que um, o país possui vantagens comparativas, se for menor, o país não possui vantagens comparativas no setor e se for igual a um, as exportações do setor crescem na mesma proporção que o crescimento mundial.

A fórmula do indicador é a seguinte:

$$
V C R=\frac{X_{i j} / X_{j}}{X_{i} / X}
$$

Onde:

$\mathrm{X}_{\mathrm{ij}}=$ exportações do grupo setorial i pelo país $\mathrm{j}$

$\mathrm{X}_{\mathrm{j}}=$ exportações totais realizadas pelo país $\mathrm{j}$

$\mathrm{X}_{\mathrm{i}}=$ exportações do grupo setorial i no mundo

$\mathrm{X}=$ exportações mundiais totais

A Contribuição ao Saldo (CS) indica qual a real contribuição do setor para a balança comercial do país. Se o resultado obtido for maior que zero, o setor contribui positivamente para o saldo comercial, caso contrário, a contribuição é negativa. 
O indicador é obtido pela seguinte fórmula:

$$
\begin{gathered}
C S=1000 \div P I B_{j} \times\left(S_{1}-S_{2}\right), \text { sendo: } \\
S_{1}=100 \times\left(X_{i j}-M_{i j}\right) /\left[\left(X_{j}+M_{j} / 2\right)\right] \\
S_{2}=100 \times\left(X_{j}-M_{j}\right) /\left[\left(X_{j}+M_{j} / 2\right)\right] \times\left[\left(X_{i j}+M_{i j}\right) / X_{j}+M_{j}\right]
\end{gathered}
$$

Onde:

$\mathrm{X}_{\mathrm{ij}}=$ exportações do grupo setorial i pelo país $\mathrm{j}$

$\mathrm{M}_{\mathrm{ij}}=$ importações do grupo setorial i pelo país $\mathrm{j}$

$\mathrm{X}_{\mathrm{j}}=$ exportações totais realizadas pelo país $\mathrm{j}$

$\mathrm{M}_{\mathrm{j}}=$ importações totais realizadas pelo país $\mathrm{j}$

$\mathrm{PIB}_{\mathrm{j}}=$ Produto Interno Bruto do país j

Como o Índice de Contribuição ao Saldo também utiliza dados das importações, que não disponíveis no Comtrade, sua análise é feita por meio de dados da OMC, que adota uma classificação setorial diferente das utilizadas para os outros indicadores, contudo essa diferença não causa grandes impactos sobre os resultados alcançados.

Sendo assim, uma vez expostos todos os aspectos metodológicos da pesquisa, a seguir são apresentados os resultados obtidos com as respectivas discussões acerca dos aspectos tecnológicos, da demanda e da contribuição ao saldo.

\section{Resultados e discussão}

Com base nos indicadores apresentados, a competitividade das exportações dos países foi analisada sob duas perspectivas, por meio da análise schumpeteriana e da análise keynesiana. $\mathrm{Na}$ perspectiva schumpeteriana, foram observados os indicadores de desempenho: market share (\%), exportações (\%) e VCR, a fim de medir qual a participação dos setores mais intensivos em tecnologia de cada país tanto no comércio mundial quanto em sua pauta de exportações, além de analisar em quais setores há especialização produtiva. A análise keynesiana será feita a partir dos resultados obtidos com base na matriz de competitividade.

\subsection{Perspectiva schumpeteriana}

De acordo com a perspectiva schumpeteriana, os melhores indicadores de comércio internacional devem ser apresentados pelos setores com maior conteúdo tecnológico, uma vez que, quando estes são bem desenvolvidos garantem a perpetuidade dos processos inovação tecnológica, tendo em vista o aprendizado obtido por meio da rotina produtiva e, além disso, apresentam produtos com maior valor agregado. Por isso, apesar de um alto market share e VCR maior que um 
serem desejáveis em todos os grupos de setores, é preferível que estejam nos setores de maior nível tecnológico e que estes também representem a maior parte da pauta de exportações, pois possuem maior elasticidade renda e demanda menos volátil.

Nesse sentido, a evolução apresentada pelo Brasil até o ano de 2007 mostra que o País continua sendo competitivo somente em setores menos intensivos em tecnologia, apenas Produtos Primários, Intensiva em Recursos Naturais e Intensiva em Escala (TABELA 4) e PP, RB1, RB2 e MT2 (TABELA 5) apresentaram VCR acima de um. E, por consequência, sua pauta de exportações é profundamente dependente desses setores, ambas as classificações apontam que mais de $50 \%$ do total exportado estão em Produtos Primários e Intensivos/Baseados em Recursos Naturais; vale destacar também que o percentual de exportações dos Produtos Primários (Laplane et al.) e RB2 aumentou durante o período, o que pode ser explicado pela forte elevação da demanda da China por esses produtos. E essa mesma tendência se reflete nos valores de market share obtidos pelo país.

No entanto, cabe também ressaltar uma pequena mudança no perfil tecnológico, com o aumento da relevância dos setores de média e alta tecnologia em detrimento dos setores de baixa tecnologia, com destaque para os setores Intensivos em P\&D e AT2, com variação de market share de $21,75 \%$ e $171,15 \%$, respectivamente, e de participação nas exportações de 126,13\% e 354,33\%. O que se caracteriza como um fator positivo para o País, ainda que essa mudança se apresente de forma branda, uma vez que, apesar da evolução, esses setores ainda possuem valores absolutos muito baixos.

Quanto à Rússia pode-se dizer que, sob a perspectiva schumpeteriana, é quem apresenta o pior padrão de especialização entre todos os países dos BRICS, o país que já era muito dependente dos setores de menor intensidade tecnológica em 1991, com Produtos Primários e Intensivos/Baseados em Recursos Naturais representado 62,44\% e 68,97\% das exportações nas classificações de Laplane et al. e Lall e Albaladejo, respectivamente, aumentou sua dependência durante o período e em 2007 tinha mais de 76\% do total exportado representado por esses grupos de setores. Um ponto significativo dessa característica pode ser destacado na TABELA 4, segundo a qual os Produtos Primários aumentaram sua participação em 70,79\%, em detrimento da participação de todos os demais setores.

Esse atributo da Economia russa é observado nos demais indicadores, uma vez que somente esses setores possuem VCR acima de um e participação de mercado significativa. Além disso, destaca-se o fato de que os setores mais intensivos em tecnologia são os que apresentam piores resultados, uma vez que os setores, além possuírem baixo VCR e perderam importância na pauta exportadora, também perderam market share. 
$\mathrm{Na}$ Índia dois pontos podem ser destacados, primeiro a forte competitividade e dependência do grupo Intensivos em Trabalho (TABELA 4) e RB2 e LT1 (TABELA 5), com percentual de exportação de $41,74 \%$ e $49,85 \%$, respectivamente, e segundo a pequena participação no mercado mundial para um país do seu porte, refletindo o grau de fechamento de sua Economia durante quase todo o século XX. No entanto, assim como no Brasil, os setores mais intensivos em tecnologia têm ganhado competitividade na Índia e, em decorrência, maior market share e participação no total exportado, nesse caso, em detrimento principalmente dos Produtos Primários (ambas as classificações), que deixou de ser uma especialização produtiva do país (VCR menor que um), contudo esses resultados são relativizados, uma vez que o país possui pouca representatividade na participação de mercado mundial.

Tabela $4^{6}$ : Indicadores de desempenho exportador (Laplane et al.)

\begin{tabular}{|c|c|c|c|c|c|c|c|c|}
\hline \multirow{2}{*}{$\begin{array}{l}\text { Classificação } \\
\text { Produtos Primários }\end{array}$} & \multicolumn{3}{|c|}{ Market share (\%) } & \multicolumn{3}{|c|}{ Exportações (\%) } & \multicolumn{2}{|c|}{ VCR } \\
\hline & Ano 1 & Ano 2 & Variação & Ano 1 & Ano 2 & Variação & Ano 1 & Ano 2 \\
\hline Brasil & 2,15 & 3,20 & 48,63 & 30,18 & 34,73 & 15,08 & 1,56 & 2,44 \\
\hline Rússia & 2,34 & 5,98 & 156,04 & 32,62 & 55,71 & 70,79 & 2,39 & 3,91 \\
\hline Índia & 0,75 & 0,92 & 23,20 & 30,04 & 14,04 & $-53,25$ & 1,56 & 0,99 \\
\hline China & 2,53 & 1,68 & $-33,85$ & 30,46 & 2,09 & $-93,13$ & 1,58 & 0,15 \\
\hline África do Sul & 1,13 & 0,89 & $-21,01$ & 31,88 & 24,20 & $-24,08$ & 1,65 & 2,24 \\
\hline Intensiva em Recursos Naturais & Ano 1 & Ano 2 & Variação & Ano 1 & Ano 2 & Variação & Ano 1 & Ano 2 \\
\hline Brasil & 1,99 & 2,02 & 1,35 & 27,18 & 18,02 & $-33,71$ & 1,45 & 1,54 \\
\hline Rússia & 1,79 & 2,68 & 49,86 & 29,82 & 20,51 & $-31,24$ & 1,83 & 1,75 \\
\hline Índia & 0,34 & 1,18 & 243,31 & 13,41 & 14,76 & 10,05 & 0,71 & 1,26 \\
\hline China & 1,43 & 5,60 & 291,00 & 16,78 & 5,76 & $-65,70$ & 0,89 & 0,49 \\
\hline África do Sul & 1,56 & 1,18 & $-24,49$ & 42,81 & 41,61 & $-2,79$ & 2,28 & 2,96 \\
\hline Intensiva em Trabalho & Ano 1 & Ano 2 & Variação & Ano 1 & Ano 2 & Variação & Ano 1 & Ano 2 \\
\hline Brasil & 1,11 & 0,75 & $-33,00$ & 11,36 & 7,76 & $-31,66$ & 0,81 & 0,57 \\
\hline Rússia & 0,20 & 0,28 & 44,16 & 3,49 & 2,54 & $-27,17$ & 0,20 & 0,19 \\
\hline Índia & 1,49 & 2,86 & 92,46 & 43,40 & 41,74 & $-3,83$ & 3,08 & 3,05 \\
\hline China & 4,56 & 26,31 & 477,44 & 39,98 & 31,58 & $-21,01$ & 2,84 & 2,31 \\
\hline África do Sul & 0,43 & 0,28 & $-34,27$ & 8,78 & 11,39 & 29,82 & 0,62 & 0,71 \\
\hline Intensiva em Escala & Ano 1 & Ano 2 & Variação & Ano 1 & Ano 2 & Variação & Ano 1 & Ano 2 \\
\hline Brasil & 1,06 & 1,33 & 25,66 & 15,43 & 19,21 & 24,52 & 0,77 & 1,02 \\
\hline Rússia & 0,54 & 0,83 & 54,85 & 11,18 & 10,27 & $-8,14$ & 0,55 & 0,54 \\
\hline Índia & 0,15 & 0,67 & 355,78 & 6,13 & 13,54 & 120,71 & 0,31 & 0,72 \\
\hline China & 0,44 & 10,95 & 2417,24 & 5,44 & 18,18 & 234,43 & 0,27 & 0,96 \\
\hline África do Sul & 0,39 & 0,28 & $-27,53$ & 11,29 & 13,60 & 20,44 & 0,56 & 0,70 \\
\hline Fornecedores Especializados & Ano 1 & Ano 2 & Variação & Ano 1 & Ano 2 & Variação & Ano 1 & Ano 2 \\
\hline Brasil & 0,76 & 0,74 & $-2,89$ & 6,81 & 8,60 & 26,38 & 0,55 & 0,56 \\
\hline Rússia & 0,12 & 0,06 & $-49,19$ & 1,96 & 0,63 & $-67,62$ & 0,13 & 0,04 \\
\hline Índia & 0,11 & 0,42 & 293,46 & 2,74 & 6,86 & 150,93 & 0,22 & 0,45 \\
\hline China & 0,19 & 18,41 & 9641,27 & 1,46 & 24,68 & 1596,36 & 0,12 & 1,62 \\
\hline África do Sul & 0,06 & 0,11 & 86,21 & 1,05 & 4,80 & 358,60 & 0,09 & 0,27 \\
\hline Intensiva em P\&D & Ano 1 & Ano 2 & Variação & Ano 1 & Ano 2 & Variação & Ano 1 & Ano 2 \\
\hline Brasil & 0,52 & 0,63 & 21,75 & 3,29 & 7,44 & 126,13 & 0,37 & 0,48 \\
\hline Rússia & 0,27 & 0,12 & $-54,89$ & 3,09 & 1,23 & $-60,33$ & 0,27 & 0,08 \\
\hline
\end{tabular}

\footnotetext{
${ }^{6}$ Os dados da Rússia estão disponíveis a partir de 1991, quando foi dissolvida a União Soviética. E por indisponibilidade do Comtrade, a África do Sul só possui dados até o ano 2000.
} 


\begin{tabular}{lrrrrrrrr} 
Índia & 0,12 & 0,40 & 226,45 & 2,21 & 6,56 & 197,42 & 0,25 & 0,42 \\
China & 0,53 & 11,17 & 2012,29 & 2,90 & 15,26 & 426,13 & 0,33 & 0,98 \\
África do Sul & 0,11 & 0,04 & $-61,11$ & 1,39 & 1,72 & 23,95 & 0,16 & 0,11 \\
\hline
\end{tabular}

Fonte: Elaboração própria a partir de dados do Tradecan2009

Nota: Para Brasil, Índia e China os anos correspondem a 1985 e 2007, para a Rússia 1991 e 2007 e para a África do Sul 1985 e 2000.

Os resultados apresentados pela China refletem o empenho do país voltado para a competitividade produtiva e para as exportações, com exceção dos Produtos Primários (LAPLANE), todos os grupos apresentaram ganho de mercado até 2007, com muitos deles apresentando market share acima de $10 \%$, o que tornou o país um dos principais produtores do mercado mundial. Os grupos dos setores mais intensivos em tecnologia exibiram grades percentuais de ganho de mercado e aumentaram sua relevância na participação nas exportações, com destaque na Tabela 4 para Fornecedores Especializados, que ganhou 9.641,27\% de market share, passando de $0,19 \%$ para $18,41 \%$ de participação de mercado e Intensivos em P\&D passando de 0,53\% para 11,17\%, o que representou um ganho mercado de 2.012,29\%. Já na Tabela 5 se destacam MT3, com variação de $2.930,41 \%$, obtendo $13,46 \%$ do mercado e AT1 com o ganho de $8.874,46 \%$, passando de $0,28 \%$ para $24,95 \%$ de market share. Além disso, a maior parte desses grupos possui especialização produtiva ou está próximo de apresentar VCR igual a um, evidenciando o maior esforço competitivo dentro da perspectiva schumpeteriana.

Tabela $5^{7}$ : Indicadores de desempenho exportador (Lall e Albaladejo)

\begin{tabular}{|c|c|c|c|c|c|c|c|c|}
\hline Classificação & \multicolumn{3}{|c|}{ Market share (\%) } & \multicolumn{3}{|c|}{ Exportações (\%) } & \multicolumn{2}{|c|}{ VCR } \\
\hline PP & Ano 1 & Ano 2 & Variação & Ano 1 & Ano 2 & Variação & Ano 1 & Ano 2 \\
\hline Brasil & 1,84 & 2,37 & 28,71 & 35,10 & 29,25 & $-16,67$ & 1,34 & 1,80 \\
\hline Rússia & 2,45 & 6,10 & 149,37 & 46,22 & 64,66 & 39,90 & 2,50 & 3,99 \\
\hline Índia & 0,59 & 0,62 & 5,06 & 32,35 & 10,78 & $-66,68$ & 1,23 & 0,67 \\
\hline China & 2,34 & 2,41 & 3,03 & 38,33 & 3,43 & $-91,05$ & 1,46 & 0,21 \\
\hline África do Sul & 1,04 & 0,92 & $-11,91$ & 40,06 & 35,05 & $-12,52$ & 1,52 & 2,31 \\
\hline RB1 & Ano 1 & Ano 2 & Variação & Ano 1 & Ano 2 & Variação & Ano 1 & Ano 2 \\
\hline Brasil & 2,83 & 3,18 & 12,37 & 14,45 & 11,62 & $-19,63$ & 2,05 & 2,42 \\
\hline Rússia & 0,78 & 1,72 & 120,72 & 5,83 & 5,38 & $-7,79$ & 0,79 & 1,12 \\
\hline Índia & 0,21 & 0,41 & 100,00 & 3,02 & 2,11 & $-29,98$ & 0,43 & 0,44 \\
\hline China & 0,95 & 5,60 & 486,48 & 4,19 & 2,35 & $-43,75$ & 0,59 & 0,49 \\
\hline África do Sul & 0,58 & 0,38 & $-34,93$ & 6,02 & 5,70 & $-5,30$ & 0,86 & 0,96 \\
\hline RB2 & Ano 1 & Ano 2 & Variação & Ano 1 & Ano 2 & Variação & Ano 1 & Ano 2 \\
\hline Brasil & 2,11 & 3,53 & 67,08 & 16,26 & 17,69 & 8,83 & 1,53 & 2,69 \\
\hline Rússia & 1,98 & 1,56 & $-21,45$ & 16,92 & 6,70 & $-60,39$ & 2,03 & 1,02 \\
\hline Índia & 1,27 & 4,12 & 225,67 & 27,87 & 28,97 & 3,96 & 2,63 & 4,40 \\
\hline China & 1,31 & 5,49 & 319,82 & 8,64 & 3,17 & $-63,35$ & 0,82 & 0,48 \\
\hline África do Sul & 1,13 & 0,85 & $-24,76$ & 17,51 & 16,46 & $-5,97$ & 1,65 & 2,14 \\
\hline LT1 & Ano 1 & Ano 2 & Variação & Ano 1 & Ano 2 & Variação & Ano 1 & Ano 2 \\
\hline Brasil & 1,85 & 1,01 & $-45,21$ & 8,72 & 4,01 & $-53,98$ & 1,34 & 0,77 \\
\hline Rússia & 0,11 & 0,08 & $-21,50$ & 0,85 & 0,29 & $-66,27$ & 0,11 & 0,06 \\
\hline Índia & 1,95 & 3,76 & 92,82 & 26,32 & 20,88 & $-20,67$ & 4,05 & 4,01 \\
\hline
\end{tabular}

\footnotetext{
7 Os dados da Rússia estão disponíveis a partir de 1991, quando foi dissolvida a União Soviética. E por indisponibilidade do Tradecan, a África do Sul só possui dados até o ano 2000.
} 


\begin{tabular}{|c|c|c|c|c|c|c|c|c|}
\hline China & 7,40 & 36,27 & 390,06 & 30,00 & 16,56 & $-44,81$ & 4,61 & 3,18 \\
\hline África do Sul & 0,25 & 0,18 & $-29,32$ & 2,37 & 3,02 & 27,23 & 0,37 & 0,44 \\
\hline LT2 & Ano 1 & Ano 2 & Variação & Ano 1 & Ano 2 & Variação & Ano 1 & Ano 2 \\
\hline Brasil & 0,86 & 0,76 & $-11,64$ & 4,71 & 4,83 & 2,59 & 0,62 & 0,58 \\
\hline Rússia & 0,20 & 0,53 & 167,01 & 1,80 & 2,87 & 59,40 & 0,20 & 0,34 \\
\hline Índia & 0,27 & 1,22 & 355,81 & 4,18 & 10,84 & 159,32 & 0,55 & 1,30 \\
\hline China & 1,99 & 23,38 & 1073,64 & 9,36 & 17,12 & 82,83 & 1,24 & 2,05 \\
\hline África do Sul & 0,54 & 0,23 & $-56,51$ & 5,95 & 5,11 & $-14,04$ & 0,79 & 0,59 \\
\hline MT1 & Ano 1 & Ano 2 & Variação & Ano 1 & Ano 2 & Variação & Ano 1 & Ano 2 \\
\hline Brasil & 0,57 & 1,28 & 123,34 & 3,76 & 7,82 & 108,15 & 0,42 & 0,98 \\
\hline Rússia & 0,39 & 0,02 & $-95,63$ & 3,57 & 0,09 & $-97,51$ & 0,40 & 0,01 \\
\hline Índia & 0,04 & 0,27 & 652,78 & 0,67 & 2,31 & 246,78 & 0,07 & 0,29 \\
\hline China & 0,03 & 1,79 & 5170,59 & 0,19 & 1,26 & 555,21 & 0,02 & 0,16 \\
\hline África do Sul & 0,03 & 0,14 & 442,31 & 0,35 & 3,22 & 826,80 & 0,04 & 0,36 \\
\hline MT2 & Ano 1 & Ano 2 & Variação & Ano 1 & Ano 2 & Variação & Ano 1 & Ano 2 \\
\hline Brasil & 1,62 & 1,72 & 5,60 & 7,78 & 9,07 & 16,50 & 1,18 & 1,31 \\
\hline Rússia & 1,41 & 2,14 & 51,56 & 10,81 & 9,71 & $-10,18$ & 1,44 & 1,40 \\
\hline Índia & 0,09 & 0,99 & 977,17 & 1,25 & 7,34 & 485,57 & 0,19 & 1,06 \\
\hline China & 0,96 & 6,07 & 533,09 & 3,94 & 3,69 & $-6,27$ & 0,60 & 0,53 \\
\hline África do Sul & 0,80 & 0,43 & $-45,79$ & 7,68 & 7,09 & $-7,64$ & 1,16 & 1,09 \\
\hline MT3 & Ano 1 & Ano 2 & Variação & Ano 1 & Ano 2 & Variação & Ano 1 & Ano 2 \\
\hline Brasil & 0,85 & 0,85 & $-0,82$ & 7,48 & 8,10 & 8,36 & 0,62 & 0,65 \\
\hline Rússia & 0,18 & 0,07 & $-60,45$ & 2,47 & 0,58 & $-76,72$ & 0,18 & 0,05 \\
\hline Índia & 0,15 & 0,45 & 194,70 & 3,79 & 5,97 & 57,48 & 0,31 & 0,48 \\
\hline China & 0,44 & 13,46 & 2930,41 & 3,34 & 14,82 & 344,15 & 0,28 & 1,18 \\
\hline África do Sul & 0,05 & 0,16 & 209,43 & 0,93 & 5,48 & 487,55 & 0,08 & 0,41 \\
\hline AT1 & Ano 1 & Ano 2 & Variação & Ano 1 & Ano 2 & Variação & Ano 1 & Ano 2 \\
\hline Brasil & 0,40 & 0,36 & $-10,15$ & 2,40 & 4,11 & 71,52 & 0,29 & 0,28 \\
\hline Rússia & 0,06 & 0,04 & $-38,98$ & 0,67 & 0,35 & $-48,20$ & 0,06 & 0,02 \\
\hline Índia & 0,07 & 0,25 & 238,36 & 1,23 & 3,92 & 217,50 & 0,15 & 0,26 \\
\hline China & 0,28 & 24,95 & 8874,46 & 1,41 & 32,47 & 2196,53 & 0,17 & 2,19 \\
\hline África do Sul & 0,07 & 0,03 & $-59,09$ & 0,79 & 1,19 & 50,82 & 0,10 & 0,07 \\
\hline AT2 & Ano 1 & Ano 2 & Variação & Ano 1 & Ano 2 & Variação & Ano 1 & Ano 2 \\
\hline Brasil & 0,25 & 0,69 & 171,15 & 0,68 & 3,09 & 354,33 & 0,18 & 0,52 \\
\hline Rússia & 0,74 & 0,42 & $-43,07$ & 3,62 & 1,64 & $-54,69$ & 0,76 & 0,28 \\
\hline Índia & 0,13 & 0,45 & 250,00 & 0,99 & 2,83 & 186,63 & 0,27 & 0,48 \\
\hline China & 0,52 & 4,72 & 812,77 & 1,19 & 2,45 & 105,45 & 0,32 & 0,41 \\
\hline África do Sul & 0,58 & 0,07 & $-88,66$ & 3,16 & 0,90 & $-71,60$ & 0,85 & 0,17 \\
\hline
\end{tabular}

Fonte: Elaboração própria a partir de dados do Tradecan2009

Nota: Para Brasil, Îndia e China os anos correspondem a 1985 e 2007, para a Rússia 1991 e 2007 e para a África do Sul 1985 e 2000.

A forte elevação da competitividade dos setores mais intensivos em tecnologia diminuiu a importância de outros setores, em especial dos Produtos Primários, que evoluíram, mas não na mesma velocidade e, por isso, apresentaram participação quase irrelevante na pauta de exportações do país, Produtos Primários (Tabela 4) representou apenas 2,09\% do total exportado em 2007 e PP (Tabela 5) 3,43\%, quando em 1985 possuíam mais de 30\% de participação.

Portanto, pode-se inferir que no grupo dos BRICS a China foi o único país que durante o período analisado, de fato, conseguiu promover mudança no seu perfil produtivo, em que os setores com maior conteúdo tecnológico possuem maior relevância. Contudo, é importante destacar que os setores Intensivos em Trabalho e de Baixa Tecnologia ainda possuem grande importância dentro da pauta de exportações do país com um total de $31,58 \%$ e $33,68 \%$, respectivamente. 
Já a África do Sul ficou para trás na competição pelos mercados ao longo do período, perdendo market share em praticamente todos os setores, com exceção dos Fornecedores Especializados, MT1 e MT3. O país também apresenta uma pauta de exportações muito dependente dos setores de menor intensidade tecnológica com $41,61 \%$ do total exportado concentrado somente em Intensiva em Recursos Naturais (Tabela 4). Além disso, somente Produtos Primários, Intensiva em Recursos Naturais, PP, RB2 e MT2 possuem especialização produtiva. E, embora se verifique um aumento relativo da participação de setores mais intensivos em tecnologia, isto não pode ser considerado como consequência de um esforço de mudança do perfil produtivo, mas sim um efeito provocado pela maior demanda mundial por esse tipo de produto, assim como seu maior valor agregado.

Os BRICS, portanto, de acordo com a perspectiva de competitividade schumpeteriana, podem ser divididos em três grupos, o primeiro representado pela China que possui um perfil produtivo diferente do apresentado no início do período, com o aumento da relevância dos setores mais intensivos em tecnologia. No segundo, estão Brasil e Índia, que apresentam um pequeno esforço na direção da maior competitividade e participação dos setores mais tecnológicos, contudo o seu foco produtivo ainda está nos setores em que apresentam maiores vantagens comparativas. E Rússia e África do Sul compõem o terceiro grupo, cujos países perderam competitividade dentro da perspectiva schumpeteriana, com exceção de Fornecedores Especializados e MT3 na África do Sul (o que não altera as conclusões apresentadas).

Vale salientar também que o caso dos BRICS mostra como a força do princípio das vantagens comparativas de Ricardo ainda está muito presente no comércio internacional. Em todos os países do grupo, os setores em que cada um possui maior vantagem comparativa continuam sendo muito importantes na sua pauta de exportação - Produtos Primários e baseados em Recursos Naturais no caso de Brasil, Rússia e África do Sul e Intensivos em Trabalho no caso de Índia e China - ainda que não sejam os mais atrativos para a competitividade no comércio internacional dos países, mesmo na China que é dona do melhor perfil produtivo do grupo esse princípio ainda pode ser verificado.

A partir de 2008, o mundo passou a enfrentar uma grave crise econômica, que se deflagrou nos Estados Unidos e, posteriormente, teve início a crise da dívida europeia em 2010. A partir desses eventos a onda de crescimento pela qual passava a Economia mundial acabou e os países dos BRICS tiveram de enfrentar novos desafios em seu processo de inserção internacional. No que tange ao comércio, as mudanças ocorridas no período até o ano de 2012 não foram suficientes para caracterizar uma reversão da estrutura produtiva construída ao longo dos anos anteriores, mas 
alguns dos valores apresentados nas Tabelas 6 e 7 evidenciam particularidades importantes dos países do grupo.

De acordo com os dados, o Brasil foi o país que pior se apresentou no período de crise, perdeu participação de mercado em, praticamente, todos os grupos de maior intensidade tecnológica (com exceção de AT2), aumentando sua dependência em setores menos intensivos em tecnologia, a participação nas exportações de Produtos Primários e Intensiva em Trabalho e PP e Baseados em recursos naturais passou de $52,72 \%$ para $63,53 \%$ e de $58,56 \%$ para $66,81 \%$, respectivamente. Houve perdas em grupos importantes como Intensiva em Escala e MT1 e mesmo AT2, grupo que obteve ganho de mercado, perdeu participação no total exportado, no entanto essas perdas ainda não podem ser definidas como uma completa regressão do País, embora, no momento, esteja mais próximo da caracterização feita anteriormente para a Rússia.

Essa, por sua vez, apresentou uma pequena mudança após 2007, apesar da continuação da forte dependência dos grupos menos intensivos em tecnologia e do forte crescimento de setores dos grupos Intensiva em Recursos Naturais, com aumento de 85,97\% de market share e de 40,57\% no percentual de exportações, e RB2, com crescimento de 292,69\% de participação de mercado e de $251,77 \%$ no total exportado. Diferentemente, da característica apresentada anteriormente, nesse período, o país sinalizou uma pequena tendência à diversificação, com o crescimento tanto de market share quanto de participação de exportações de setores mais intensivos em tecnologia. No entanto, deve-se ressaltar novamente que essas mudanças ainda não podem determinar a reversão da estrutura produtiva do país.

Tabela 6: Indicadores de desempenho exportador - pós-crise (Laplane et al.)

\begin{tabular}{l|r|r|r|r|r|r|r|r}
\hline \multicolumn{1}{c|}{ Classificação } & \multicolumn{3}{|c|}{ Market share (\%) } & \multicolumn{2}{c|}{ Exportações (\%) } & \multicolumn{2}{c}{ VCR } \\
\hline Produtos Primários & Ano 2 & $\mathbf{2 0 1 2}$ & Variação & Ano 2 & $\mathbf{2 0 1 2}$ & \multicolumn{1}{c}{ Variação } & Ano 2 & $\mathbf{2 0 1 2}$ \\
\hline Brasil & 3,20 & 4,77 & 49,17 & 34,73 & 43,80 & 26,12 & 2,44 & 3,37 \\
Rússia & 5,98 & 9,71 & 62,29 & 55,71 & 41,17 & $-26,10$ & 3,91 & 3,17 \\
Índia & 0,92 & 1,15 & 24,27 & 14,04 & 8,83 & $-37,14$ & 0,99 & 0,68 \\
China & 1,68 & 1,85 & 10,45 & 2,09 & 2,01 & $-3,93$ & 0,15 & 0,15 \\
África do Sul & 0,89 & 1,13 & 26,63 & 24,20 & 28,96 & 19,68 & 2,24 & 2,23 \\
\hline Intensiva em Recursos Naturais & Ano 2 & $\mathbf{2 0 1 2}$ & Variação & Ano 2 & $\mathbf{2 0 1 2}$ & Variação & Ano 2 & $\mathbf{2 0 1 2}$ \\
\hline Brasil & 2,02 & 1,58 & $-21,99$ & 18,02 & 19,73 & 9,50 & 1,54 & 1,11 \\
Rússia & 2,68 & 4,98 & 85,97 & 20,51 & 28,82 & 40,57 & 1,75 & 1,63 \\
Índia & 1,18 & 2,80 & 136,72 & 14,76 & 29,32 & 98,72 & 1,26 & 1,66 \\
China & 5,60 & 5,08 & $-9,35$ & 5,76 & 7,53 & 30,82 & 0,49 & 0,43 \\
África do Sul & 1,18 & 0,93 & $-20,87$ & 41,61 & 32,56 & $-21,75$ & 2,96 & 1,84 \\
\hline Intensiva em Trabalho & Ano 2 & $\mathbf{2 0 1 2}$ & Variação & Ano 2 & $\mathbf{2 0 1 2}$ & Variação & Ano 2 & $\mathbf{2 0 1 2}$ \\
\hline Brasil & 0,75 & 0,48 & $-36,00$ & 7,76 & 4,46 & $-42,53$ & 0,57 & 0,34 \\
Rússia & 0,28 & 0,47 & 65,19 & 2,54 & 2,03 & $-20,13$ & 0,19 & 0,15 \\
Índia & 2,86 & 3,70 & 29,29 & 41,74 & 28,97 & $-30,60$ & 3,05 & 2,19 \\
China & 26,31 & 25,95 & $-1,38$ & 31,58 & 28,75 & $-8,96$ & 2,31 & 2,17 \\
África do Sul & 0,28 & 0,20 & $-29,23$ & 11,39 & 5,19 & $-54,47$ & 0,71 & 0,39
\end{tabular}




\begin{tabular}{|c|c|c|c|c|c|c|c|c|}
\hline Intensiva em Escala & Ano 2 & 2012 & Variação & Ano 2 & 2012 & Variação & Ano 2 & 2012 \\
\hline Brasil & 1,33 & 1,05 & $-21,03$ & 19,21 & 13,55 & $-29,49$ & 1,02 & 0,74 \\
\hline Rússia & 0,83 & 1,11 & 34,27 & 10,27 & 6,63 & $-35,43$ & 0,54 & 0,36 \\
\hline Índia & 0,67 & 1,32 & 97,24 & 13,54 & 14,26 & 5,32 & 0,72 & 0,78 \\
\hline China & 10,95 & 12,71 & 16,05 & 18,18 & 19,38 & 6,56 & 0,96 & 1,06 \\
\hline África do Sul & 0,28 & 0,56 & 100,23 & 13,60 & 20,12 & 47,97 & 0,70 & 1,10 \\
\hline Fornecedores Especializados & Ano 2 & 2012 & Variação & Ano 2 & 2012 & Variação & Ano 2 & 2012 \\
\hline Brasil & 0,74 & 0,68 & $-8,50$ & 8,60 & 7,00 & $-18,68$ & 0,56 & 0,48 \\
\hline Rússia & 0,06 & 0,43 & 576,22 & 0,63 & 2,04 & 221,89 & 0,04 & 0,14 \\
\hline Índia & 0,42 & 0,60 & 42,71 & 6,86 & 5,21 & $-24,12$ & 0,45 & 0,36 \\
\hline China & 18,41 & 18,47 & 0,30 & 24,68 & 22,62 & $-8,34$ & 1,62 & 1,55 \\
\hline África do Sul & 0,11 & 0,24 & 122,32 & 4,80 & 6,95 & 44,88 & 0,27 & 0,47 \\
\hline Intensiva em P\&D & Ano 2 & 2012 & Variação & Ano 2 & 2012 & Variação & Ano 2 & 2012 \\
\hline Brasil & 0,63 & 0,50 & $-19,62$ & 7,44 & 5,43 & $-27,03$ & 0,48 & 0,36 \\
\hline Rússia & 0,12 & 0,25 & 107,60 & 1,23 & 1,24 & 1,19 & 0,08 & 0,08 \\
\hline Índia & 0,40 & 0,97 & 144,54 & 6,56 & 8,71 & 32,76 & 0,42 & 0,57 \\
\hline China & 11,17 & 14,16 & 26,68 & 15,26 & 18,04 & 18,20 & 0,98 & 1,18 \\
\hline África do Sul & 0,04 & 0,13 & 216,64 & 1,72 & 4,00 & 133,10 & 0,11 & 0,26 \\
\hline
\end{tabular}

Fonte: Elaboração própria a partir de dados do Tradecan2009 e Comtrade.

Nota: Os dados do ano 2 da África do Sul correspondem ao ano 2000.

Quanto à Índia, é possível dizer que pouco sofreu, em relação ao comércio internacional, com as crises do período. O país continuou com o processo de expansão e diversificação do comércio, ganhou market share em praticamente todos os grupos, com exceção de LT1, no qual perdeu 0,02 pontos percentuais, ultrapassando o Brasil na participação de mercado de alguns grupos, com destaque para Intensiva em Escala de 0,67\% para 1,32\%, Intensiva em P\&D de 0,40\% para $0,97 \%$ e AT2 de $0,45 \%$ para $1,39 \%$.

Apesar de cobrir um período de tempo mais curto, por meio dos dados das Tabelas 6 e 7 é possível perceber a queda do ímpeto da expansão do comércio da China, que diminuiu o ritmo de crescimento e chegou a perder participação de mercado em alguns grupos. No entanto, ainda há o aumento da importância dos grupos mais intensivos em tecnologia e a forte expansão de market share nos grupos em que seu percentual de participação não era tão grande, se comparado com os demais, como MT1, variando 129,91\% e AT2, com variação de 47,90\%.

Tabela 7: Indicadores de desempenho exportador - pós-crise (Lall e Albaladejo)

\begin{tabular}{|c|c|c|c|c|c|c|c|c|}
\hline \multirow{2}{*}{$\begin{array}{l}\text { Classificação } \\
\text { PP }\end{array}$} & \multicolumn{3}{|c|}{ Market share (\%) } & \multicolumn{3}{|c|}{ Exportações (\%) } & \multicolumn{2}{|c|}{ VCR } \\
\hline & Ano 2 & 2012 & Variação & Ano 2 & 2012 & Variação & Ano 2 & 2012 \\
\hline Brasil & 2,37 & 3,35 & 41,47 & 29,25 & 34,46 & 17,83 & 1,80 & 2,37 \\
\hline Rússia & 6,10 & 8,90 & 45,93 & 64,66 & 42,33 & $-34,53$ & 3,99 & 2,91 \\
\hline Índia & 0,62 & 1,37 & 119,88 & 10,78 & 11,81 & 9,57 & 0,67 & 0,81 \\
\hline China & 2,41 & 2,41 & 0,05 & 3,43 & 2,94 & $-14,30$ & 0,21 & 0,20 \\
\hline África do Sul & 0,92 & 0,94 & 2,32 & 35,05 & 27,01 & $-22,92$ & 2,31 & 1,86 \\
\hline RB1 & Ano 2 & 2012 & Variação & Ano 2 & 2012 & Variação & Ano 2 & 2012 \\
\hline Brasil & 3,18 & 3,55 & 11,65 & 11,62 & 12,49 & 7,51 & 2,42 & 2,51 \\
\hline Rússia & 1,72 & 1,65 & $-3,89$ & 5,38 & 2,68 & $-50,14$ & 1,12 & 0,54 \\
\hline Índia & 0,41 & 0,93 & 126,08 & 2,11 & 2,75 & 30,06 & 0,44 & 0,55 \\
\hline
\end{tabular}




\begin{tabular}{|c|c|c|c|c|c|c|c|c|}
\hline $\begin{array}{l}\text { China } \\
\text { África do Sul }\end{array}$ & $\begin{array}{l}5,60 \\
0,38 \\
\end{array}$ & $\begin{array}{l}7,32 \\
0,49 \\
\end{array}$ & $\begin{array}{l}30,80 \\
28,57 \\
\end{array}$ & $\begin{array}{l}2,35 \\
5,70 \\
\end{array}$ & $\begin{array}{l}3,05 \\
4,81 \\
\end{array}$ & $\begin{array}{r}29,51 \\
-15,66 \\
\end{array}$ & $\begin{array}{l}0,49 \\
0,96 \\
\end{array}$ & $\begin{array}{l}0,61 \\
0,97 \\
\end{array}$ \\
\hline RB2 & Ano 2 & 2012 & Variação & Ano 2 & 2012 & Variação & Ano 2 & 2012 \\
\hline Brasil & 3,53 & 2,38 & $-32,55$ & 17,69 & 19,86 & 12,23 & 2,69 & 1,68 \\
\hline Rússia & 1,56 & 6,11 & 292,69 & 6,70 & 23,57 & 251,77 & 1,02 & 2,00 \\
\hline Índia & 4,12 & 4,73 & 14,67 & 28,97 & 33,06 & 14,10 & 4,40 & 2,80 \\
\hline China & 5,49 & 4,95 & $-9,77$ & 3,17 & 4,89 & 54,42 & 0,48 & 0,41 \\
\hline África do Sul & 0,85 & 0,99 & 16,35 & 16,46 & 23,04 & 39,93 & 2,14 & 1,95 \\
\hline LT1 & Ano 2 & 2012 & Variação & Ano 2 & 2012 & Variação & Ano 2 & 2012 \\
\hline Brasil & 1,01 & 0,55 & $-45,89$ & 4,01 & 1,85 & $-53,92$ & 0,77 & 0,39 \\
\hline Rússia & 0,08 & 0,13 & 51,59 & 0,29 & 0,20 & $-30,74$ & 0,06 & 0,04 \\
\hline Índia & 3,76 & 3,74 & $-0,63$ & 20,88 & 10,57 & $-49,38$ & 4,01 & 2,21 \\
\hline China & 36,27 & 36,92 & 1,78 & 16,56 & 14,76 & $-10,84$ & 3,18 & 3,09 \\
\hline África do Sul & 0,18 & 0,07 & $-60,88$ & 3,02 & 0,65 & $-78,45$ & 0,44 & 0,14 \\
\hline LT2 & Ano 2 & 2012 & Variação & Ano 2 & 2012 & Variação & Ano 2 & 2012 \\
\hline Brasil & 0,76 & 0,55 & $-28,05$ & 4,83 & 3,19 & $-34,00$ & 0,58 & 0,39 \\
\hline Rússia & 0,53 & 0,78 & 49,12 & 2,87 & 2,11 & $-26,41$ & 0,34 & 0,26 \\
\hline Índia & 1,22 & 2,49 & 104,65 & 10,84 & 12,17 & 12,26 & 1,30 & 1,47 \\
\hline China & 23,38 & 22,88 & $-2,15$ & 17,12 & 15,80 & $-7,70$ & 2,05 & 1,91 \\
\hline África do Sul & 0,23 & 0,26 & 12,49 & 5,11 & 4,30 & $-15,95$ & 0,59 & 0,52 \\
\hline MT1 & Ano 2 & 2012 & Variação & Ano 2 & 2012 & Variação & Ano 2 & 2012 \\
\hline Brasil & 1,28 & 0,96 & $-24,75$ & 7,82 & 4,89 & $-37,49$ & 0,98 & 0,68 \\
\hline Rússia & 0,02 & 0,21 & 1155,59 & 0,09 & 0,50 & 461,62 & 0,01 & 0,07 \\
\hline Índia & 0,27 & 0,92 & 241,32 & 2,31 & 3,93 & 69,71 & 0,29 & 0,55 \\
\hline China & 1,79 & 4,12 & 129,91 & 1,26 & 2,47 & 96,44 & 0,16 & 0,35 \\
\hline África do Sul & 0,14 & 0,60 & 326,58 & 3,22 & 8,52 & 165,05 & 0,36 & 1,20 \\
\hline MT2 & Ano 2 & 2012 & Variação & Ano 2 & 2012 & Variação & Ano 2 & 2012 \\
\hline Brasil & 1,72 & 1,44 & $-15,93$ & 9,07 & 7,24 & $-20,13$ & 1,31 & 1,02 \\
\hline Rússia & 2,14 & 2,81 & 31,38 & 9,71 & 6,53 & $-32,77$ & 1,40 & 0,92 \\
\hline Índia & 0,99 & 1,59 & 60,78 & 7,34 & 6,70 & $-8,69$ & 1,06 & 0,94 \\
\hline China & 6,07 & 8,63 & 42,26 & 3,69 & 5,13 & 38,99 & 0,53 & 0,72 \\
\hline África do Sul & 0,43 & 0,75 & 72,86 & 7,09 & 10,47 & 47,59 & 1,09 & 1,47 \\
\hline MT3 & Ano 2 & 2012 & Variação & Ano 2 & 2012 & Variação & Ano 2 & 2012 \\
\hline Brasil & 0,85 & 0,74 & $-12,05$ & 8,10 & 6,98 & $-13,81$ & 0,65 & 0,53 \\
\hline Rússia & 0,07 & 0,40 & 467,24 & 0,58 & 1,72 & 199,32 & 0,05 & 0,13 \\
\hline Índia & 0,45 & 0,82 & 83,30 & 5,97 & 6,41 & 7,38 & 0,48 & 0,48 \\
\hline China & 13,46 & 14,46 & 7,50 & 14,82 & 16,06 & 8,38 & 1,18 & 1,21 \\
\hline África do Sul & 0,16 & 0,27 & 61,64 & 5,48 & 6,95 & 26,99 & 0,41 & 0,52 \\
\hline AT1 & Ano 2 & 2012 & Variação & Ano 2 & 2012 & Variação & Ano 2 & 2012 \\
\hline Brasil & 0,36 & 0,22 & $-39,10$ & 4,11 & 2,07 & $-49,54$ & 0,28 & 0,16 \\
\hline Rússia & 0,04 & 0,22 & 506,34 & 0,35 & 0,95 & 174,23 & 0,02 & 0,07 \\
\hline Índia & 0,25 & 0,39 & 58,26 & 3,92 & 3,07 & $-21,63$ & 0,26 & 0,23 \\
\hline China & 24,95 & 26,80 & 7,41 & 32,47 & 29,75 & $-8,39$ & 2,19 & 2,24 \\
\hline África do Sul & 0,03 & 0,07 & 158,65 & 1,19 & 1,83 & 53,93 & 0,07 & 0,14 \\
\hline AT2 & Ano 2 & 2012 & Variação & Ano 2 & 2012 & Variação & Ano 2 & 2012 \\
\hline Brasil & 0,69 & 0,75 & 8,85 & 3,09 & 3,02 & $-2,42$ & 0,52 & 0,53 \\
\hline Rússia & 0,42 & 0,30 & $-28,08$ & 1,64 & 0,57 & $-65,31$ & 0,28 & 0,10 \\
\hline Índia & 0,45 & 1,39 & 210,16 & 2,83 & 4,71 & 66,37 & 0,48 & 0,82 \\
\hline China & 4,72 & 6,98 & 47,90 & 2,45 & 3,34 & 36,33 & 0,41 & 0,58 \\
\hline África do Sul & 0,07 & 0,10 & 54,12 & 0,90 & 1,15 & 28,27 & 0,17 & 0,20 \\
\hline
\end{tabular}

Fonte: Elaboração própria a partir de dados do Tradecan2009 e Comtrade.

Nota: Os dados do ano 2 da África do Sul correspondem ao ano 2000. 
A África do Sul, assim como a Rússia, melhorou seu desempenho no período (vale salientar que por razões técnicas os dados do país cobrem o período de 2000 e 2012), aumentando seu market share em vários grupos, com exceção de Intensiva em Recursos Naturais, Intensiva em Trabalho e LT1, ressaltando que a participação de mercado do país ainda é pouco relevante no contexto mundial. Outro fator importante a ser levantado é a diversificação de sua pauta exportadora, mesmo ainda sendo bastante dependente de setores menos intensivos em tecnologia, com destaque para Intensiva em Escala, passando de 13,60\% para 20,12\% do total exportado e MT1, de 3,22\% para $8,52 \%$, os dois grupos ainda passaram a apresentar VCR superior a 1.

Portanto, de maneira geral, as crises econômicas do período não afetaram de forma significativa o comércio dos BRICS, que nos casos de China e Índia continuaram seu processo de expansão e diversificação e Rússia e África do Sul iniciaram um processo de reversão da tendência à dependência e encolhimento do comércio, a exceção fica no caso do Brasil, que perdeu parte dos ganhos da diversificação produtiva e diminuiu sua participação de mercado em alguns grupos, perdendo importância para a Índia.

\subsection{Perspectiva keynesiana}

A análise sob a perspectiva keynesiana toma como base a matriz de competitividade, que divide os setores em quatro categorias segundo a competitividade produtiva e o perfil da expansão ou retração da demanda internacional. Os setores em que a demanda internacional cresce são classificados como Ótimos ou Oportunidade Perdida e os setores em que houve aumento de competitividade são Ótimos ou Em declínio. Desse modo, quanto maior a quantidade de setores classificados como Ótimo, melhor o perfil produtivo do país, em contrapartida quanto maior a quantidade de setores na classificação Retrocesso pior o perfil do país.

Nesse contexto, a especialização produtiva do Brasil em produtos com menor intensidade tecnológica, demonstrada na perspectiva schumpeteriana, também se reflete na sua distribuição da matriz de competitividade. Esses grupos são os que apresentam maior percentual de setores em que país ganhou competitividade ao longo do período, no entanto estes também foram os grupos em que houve o menor número de setores com aumento na demanda mundial, demonstrando que o tipo de especialização produtiva do país não contribui para o aumento da sua competitividade internacional. Ainda assim, de maneira geral, o Brasil possui uma quantidade maior de setores que ganharam competitividade, 121 (Tabela 8) e 122 (Tabela 9), do que perderam. Contudo, há um grande percentual de setores com oportunidade perdida nos grupos de alta intensidade tecnológica (42,11\% em Intensivos em P\&D e 42,86\% em AT2), assim como nos intensivos em trabalho e de baixa tecnologia. 
O caso da Rússia se assemelha ao brasileiro, mas apresenta aspectos um pouco mais desfavoráveis, visto que o número de setores que ganharam e perderam competitividade no período é praticamente o mesmo, nas duas classificações, com uma pequena vantagem para os que ganharam. Contudo, é constatada a mesma especialização em produtos primários e baseados em recursos naturais e também uma alta quantidade relativa de setores de maior intensidade tecnológica, baixa tecnologia e intensivos em trabalho entre as oportunidades perdidas. A diferença do Brasil está no fato desse apresentar dados mais favoráveis nos setores de média tecnologia, intensivos em escala e fornecedores especializados. Contudo, essa comparação deve ser relativizada, uma vez que os dados da Rússia partem do ano de 1991 e, com base nesse ano, uma menor quantidade de setores apresentou aumento na demanda mundial.

Tabela $\mathbf{8}^{\mathbf{8}}$ : Distribuição da matriz de competitividade (Laplane et al.) - 1985/2007

\begin{tabular}{|c|c|c|c|c|c|c|c|}
\hline \multicolumn{8}{|c|}{ BRASIL } \\
\hline Matriz & Prod. Prim. & Rec. Nat. & Trabalho & Escala & Forn. Esp. & P\&D & TOTAL \\
\hline \multirow[t]{2}{*}{ Ótimo } & 2 & 9 & 5 & 11 & 9 & 7 & 43 \\
\hline & $5,88 \%$ & $16,98 \%$ & $12,50 \%$ & $29,73 \%$ & $33,33 \%$ & $36,84 \%$ & $20,48 \%$ \\
\hline \multirow[t]{2}{*}{ Em declínio } & 22 & 23 & 10 & 13 & 9 & 1 & 78 \\
\hline & $64,71 \%$ & $43,40 \%$ & $25,00 \%$ & $35,14 \%$ & $33,33 \%$ & $5,26 \%$ & $37,14 \%$ \\
\hline \multirow[t]{2}{*}{ Retrocesso } & 9 & 16 & 16 & 9 & 4 & 3 & 57 \\
\hline & $26,47 \%$ & $30,19 \%$ & $40,00 \%$ & $24,32 \%$ & $14,81 \%$ & $15,79 \%$ & $27,14 \%$ \\
\hline \multirow[t]{2}{*}{ Oportunidade Perdida } & 1 & 5 & 9 & 4 & 5 & 8 & 32 \\
\hline & $2,94 \%$ & $9,43 \%$ & $22,50 \%$ & $10,81 \%$ & $18,52 \%$ & $42,11 \%$ & $15,24 \%$ \\
\hline TOTAL & 34 & 53 & 40 & 37 & 27 & 19 & 210 \\
\hline \multicolumn{8}{|c|}{ RÚSSIA* } \\
\hline Matriz & Prod. Prim. & Rec. Nat. & Trabalho & Escala & Forn. Esp. & P\&D & TOTAL \\
\hline \multirow[t]{2}{*}{ Ótimo } & 3 & 10 & 4 & 6 & 4 & 5 & 32 \\
\hline & $9,68 \%$ & $18,87 \%$ & $10,00 \%$ & $16,22 \%$ & $14,81 \%$ & $26,32 \%$ & $15,46 \%$ \\
\hline \multirow[t]{2}{*}{ Em declínio } & 16 & 25 & 10 & 11 & 6 & 4 & 72 \\
\hline & $51,61 \%$ & $47,17 \%$ & $25,00 \%$ & $29,73 \%$ & $22,22 \%$ & $21,05 \%$ & $34,78 \%$ \\
\hline \multirow[t]{2}{*}{ Retrocesso } & 9 & 13 & 21 & 15 & 11 & 4 & 73 \\
\hline & $29,03 \%$ & $24,53 \%$ & $52,50 \%$ & $40,54 \%$ & $40,74 \%$ & $21,05 \%$ & $35,27 \%$ \\
\hline \multirow[t]{2}{*}{ Oportunidade Perdida } & 3 & 5 & 5 & 5 & 6 & 6 & 30 \\
\hline & $9,68 \%$ & $9,43 \%$ & $12,50 \%$ & $13,51 \%$ & $22,22 \%$ & $31,58 \%$ & $14,49 \%$ \\
\hline TOTAL & 31 & 53 & 40 & 37 & 27 & 19 & 207 \\
\hline \multicolumn{8}{|c|}{ ÍNDIA } \\
\hline Matriz & Prod. Prim. & Rec. Nat. & Trabalho & Escala & Forn. Esp. & P\&D & TOTAL \\
\hline \multirow[t]{2}{*}{ Ótimo } & 2 & 13 & 14 & 14 & 12 & 14 & 69 \\
\hline & $5,71 \%$ & $24,53 \%$ & $35,00 \%$ & $37,84 \%$ & $44,44 \%$ & $73,68 \%$ & $32,70 \%$ \\
\hline \multirow[t]{2}{*}{ Em declínio } & 22 & 32 & 23 & 21 & 13 & 4 & 115 \\
\hline & $62,86 \%$ & $60,38 \%$ & $57,50 \%$ & $56,76 \%$ & $48,15 \%$ & $21,05 \%$ & $54,50 \%$ \\
\hline \multirow[t]{2}{*}{ Retrocesso } & 10 & 7 & 3 & 1 & 0 & 0 & 21 \\
\hline & $28,57 \%$ & $13,21 \%$ & $7,50 \%$ & $2,70 \%$ & $0,00 \%$ & $0,00 \%$ & $9,95 \%$ \\
\hline \multirow[t]{2}{*}{ Oportunidade Perdida } & 1 & 1 & 0 & 1 & 2 & 1 & 6 \\
\hline & $2,86 \%$ & $1,89 \%$ & $0,00 \%$ & $2,70 \%$ & $7,41 \%$ & $5,26 \%$ & $2,84 \%$ \\
\hline TOTAL & 35 & 53 & 40 & 37 & 27 & 19 & 211 \\
\hline \multicolumn{8}{|c|}{ CHINA } \\
\hline
\end{tabular}

${ }^{8}$ Os dados da Rússia estão disponíveis a partir de 1991, quando foi dissolvida a União Soviética. E por indisponibilidade do Comtrade, a África do Sul só possui dados até o ano 2000. 


\begin{tabular}{|c|c|c|c|c|c|c|c|}
\hline Matriz & Prod. Prim. & Rec. Nat. & Trabalho & Escala & Forn. Esp. & P\&D & TOTAL \\
\hline \multirow[t]{2}{*}{ Ótimo } & 2 & 13 & 14 & 15 & 14 & 13 & 71 \\
\hline & $5,71 \%$ & $24,53 \%$ & $35,00 \%$ & $40,54 \%$ & $51,85 \%$ & $68,42 \%$ & $33,65 \%$ \\
\hline \multirow[t]{2}{*}{ Em declínio } & 20 & 35 & 25 & 22 & 13 & 4 & 119 \\
\hline & $57,14 \%$ & $66,04 \%$ & $62,50 \%$ & $59,46 \%$ & $48,15 \%$ & $21,05 \%$ & $56,40 \%$ \\
\hline \multirow[t]{2}{*}{ Retrocesso } & 12 & 4 & 1 & 0 & 0 & 0 & 17 \\
\hline & $34,29 \%$ & $7,55 \%$ & $2,50 \%$ & $0,00 \%$ & $0,00 \%$ & $0,00 \%$ & $8,06 \%$ \\
\hline \multirow[t]{2}{*}{ Oportunidade Perdida } & 1 & 1 & 0 & 0 & 0 & 2 & 4 \\
\hline & $2,86 \%$ & $1,89 \%$ & $0,00 \%$ & $0,00 \%$ & $0,00 \%$ & $10,53 \%$ & $1,90 \%$ \\
\hline TOTAL & 35 & 53 & 40 & 37 & 27 & 19 & 211 \\
\hline \multicolumn{8}{|c|}{ ÁFRICA DO SUL** } \\
\hline Matriz & Prod. Prim. & Rec. Nat. & Trabalho & Escala & Forn. Esp. & P\&D & TOTAL \\
\hline \multirow[t]{2}{*}{ Ótimo } & 1 & 6 & 11 & 6 & 11 & 6 & 41 \\
\hline & $2,94 \%$ & $11,32 \%$ & $27,50 \%$ & $16,22 \%$ & $40,74 \%$ & $31,58 \%$ & $19,52 \%$ \\
\hline \multirow[t]{2}{*}{ Em declínio } & 15 & 17 & 7 & 13 & 7 & 2 & 61 \\
\hline & $44,12 \%$ & $32,08 \%$ & $17,50 \%$ & $35,14 \%$ & $25,93 \%$ & $10,53 \%$ & $29,05 \%$ \\
\hline \multirow[t]{2}{*}{ Retrocesso } & 18 & 23 & 11 & 11 & 5 & 3 & 71 \\
\hline & $52,94 \%$ & $43,40 \%$ & $27,50 \%$ & $29,73 \%$ & $18,52 \%$ & $15,79 \%$ & $33,81 \%$ \\
\hline \multirow[t]{2}{*}{ Oportunidade Perdida } & 0 & 7 & 11 & 7 & 4 & 8 & 37 \\
\hline & $0,00 \%$ & $13,21 \%$ & $27,50 \%$ & $18,92 \%$ & $14,81 \%$ & $42,11 \%$ & $17,62 \%$ \\
\hline TOTAL & 34 & 53 & 40 & 37 & 27 & 19 & 210 \\
\hline
\end{tabular}

Fonte: Elaboração própria a partir de dados do Tradecan2009

Notas: Os percentuais correspondem ao total indicado na última linha de cada país.

* Para a Rússia a matriz de competitividade corresponde ao período 1991/2007.

** Para a África do Sul a matriz de competitividade corresponde ao período 1985/2000.

Já a Índia exibiu dados bastante favoráveis de competitividade internacional sob a perspectiva keynesiana, mais de $85 \%$ dos setores ganharam competitividade no período e alguns grupos não apresentaram setores em retrocesso e/ou com oportunidades perdidas. Destacando-se positivamente os grupos de maior conteúdo tecnológico. A China apresenta praticamente o mesmo perfil da Índia, somente com um número um pouco maior de setores que ganharam competitividade.

A perda de competitividade internacional da África do Sul também se reflete sob essa perspectiva, menos da metade dos setores ganharam competitividade, nesse caso também não pode ser observada qualquer especialização produtiva, apenas fornecedores especializados, MT2, MT3 e AT1 se demonstraram um pouco mais competitivos, no entanto, não de maneira que mereça algum destaque para o país.

Tabela 99: Distribuição da matriz de competitividade (Lall e Albaladejo) - 1985/2007

\begin{tabular}{l|c|c|c|c|c|c|c|c|c|c|c|c}
\hline \multicolumn{10}{c}{ BRASIL } \\
\hline Matriz & PP & RB1 & RB2 & LT1 & LT2 & MT1 & MT2 & MT3 & AT1 & AT2 & TOTAL \\
\hline Ótimo & 4 & 4 & 5 & 1 & 5 & 2 & 7 & 9 & 5 & 1 & $\mathbf{4 3}$ \\
& $9,52 \%$ & $13,33 \%$ & $20,83 \%$ & $5,26 \%$ & $21,74 \%$ & $40,00 \%$ & $35,00 \%$ & $31,03 \%$ & $41,67 \%$ & $14,29 \%$ & $\mathbf{2 0 , 3 8 \%}$ \\
\hline Em declínio & 24 & 15 & 9 & 4 & 6 & 3 & 7 & 7 & 2 & 2 & $\mathbf{7 9}$ \\
& $57,14 \%$ & $50,00 \%$ & $37,50 \%$ & $21,05 \%$ & $26,09 \%$ & $60,00 \%$ & $35,00 \%$ & $24,14 \%$ & $16,67 \%$ & $28,57 \%$ & $\mathbf{3 7 , 4 4 \%}$ \\
\hline Retrocesso & 14 & 10 & 4 & 10 & 8 & 0 & 2 & 7 & 1 & 1 & $\mathbf{5 7}$
\end{tabular}

${ }^{9}$ Os dados da Rússia estão disponíveis a partir de 1991, quando foi dissolvida a União Soviética. E por indisponibilidade do Comtrade, a África do Sul só possui dados até o ano 2000. 


\begin{tabular}{|c|c|c|c|c|c|c|c|c|c|c|c|}
\hline & $33,33 \%$ & $33,33 \%$ & $16,67 \%$ & $52,63 \%$ & $34,78 \%$ & $0,00 \%$ & $10,00 \%$ & $24,14 \%$ & $8,33 \%$ & $14,29 \%$ & $27,01 \%$ \\
\hline \multirow[t]{2}{*}{ Oportunidade Perdida } & 0 & 1 & 6 & 4 & 4 & 0 & 4 & 6 & 4 & 3 & 32 \\
\hline & $0,00 \%$ & $3,33 \%$ & $25,00 \%$ & $21,05 \%$ & $17,39 \%$ & $0,00 \%$ & $20,00 \%$ & $20,69 \%$ & $33,33 \%$ & $42,86 \%$ & $15,17 \%$ \\
\hline TOTAL & 42 & 30 & 24 & 19 & 23 & 5 & 20 & 29 & 12 & 7 & 211 \\
\hline \multicolumn{12}{|c|}{ RÚSSIA* } \\
\hline Matriz & $\mathbf{P P}$ & RB1 & RB2 & LT1 & LT2 & MT1 & MT2 & MT3 & AT1 & AT2 & TOTAL \\
\hline \multirow[t]{2}{*}{ Ótimo } & 7 & 2 & 5 & 0 & 3 & 0 & 6 & 5 & 4 & 0 & 32 \\
\hline & $17,07 \%$ & $7,14 \%$ & $20,83 \%$ & $0,00 \%$ & $13,04 \%$ & $0,00 \%$ & $30,00 \%$ & $17,24 \%$ & $33,33 \%$ & $0,00 \%$ & $15,38 \%$ \\
\hline \multirow[t]{2}{*}{ Em declínio } & 20 & 18 & 6 & 3 & 10 & 0 & 7 & 5 & 2 & 2 & 73 \\
\hline & $48,78 \%$ & $64,29 \%$ & $25,00 \%$ & $15,79 \%$ & $43,48 \%$ & $0,00 \%$ & $35,00 \%$ & $17,24 \%$ & $16,67 \%$ & $28,57 \%$ & $35,10 \%$ \\
\hline \multirow[t]{2}{*}{ Retrocesso } & 12 & 7 & 7 & 14 & 7 & 4 & 4 & 14 & 1 & 3 & 73 \\
\hline & $29,27 \%$ & $25,00 \%$ & $29,17 \%$ & $73,68 \%$ & $30,43 \%$ & $80,00 \%$ & $20,00 \%$ & $48,28 \%$ & $8,33 \%$ & $42,86 \%$ & $35,10 \%$ \\
\hline \multirow[t]{2}{*}{ Oportunidade Perdida } & 2 & 1 & 6 & 2 & 3 & 1 & 3 & 5 & 5 & 2 & 30 \\
\hline & $4,88 \%$ & $3,57 \%$ & $25,00 \%$ & $10,53 \%$ & $13,04 \%$ & $20,00 \%$ & $15,00 \%$ & $17,24 \%$ & $41,67 \%$ & $28,57 \%$ & $14,42 \%$ \\
\hline TOTAL & 41 & 28 & 24 & 19 & 23 & 5 & 20 & 29 & 12 & 7 & 208 \\
\hline \multicolumn{12}{|c|}{ ÍNDIA } \\
\hline Matriz & PP & RB1 & RB2 & LT1 & LT2 & MT1 & MT2 & MT3 & AT1 & AT2 & TOTAL \\
\hline \multirow[t]{2}{*}{ Ótimo } & 4 & 4 & 10 & 5 & 9 & 1 & 11 & 15 & 7 & 3 & 69 \\
\hline & $9,30 \%$ & $13,33 \%$ & $41,67 \%$ & $26,32 \%$ & $39,13 \%$ & $20,00 \%$ & $55,00 \%$ & $51,72 \%$ & $58,33 \%$ & $42,86 \%$ & $32,55 \%$ \\
\hline \multirow[t]{2}{*}{ Em declínio } & 27 & 20 & 12 & 11 & 14 & 3 & 9 & 13 & 3 & 2 & 114 \\
\hline & $62,79 \%$ & $66,67 \%$ & $50,00 \%$ & $57,89 \%$ & $60,87 \%$ & $60,00 \%$ & $45,00 \%$ & $44,83 \%$ & $25,00 \%$ & $28,57 \%$ & $\mathbf{5 3 , 7 7 \%}$ \\
\hline \multirow[t]{2}{*}{ Retrocesso } & 12 & 5 & 1 & 3 & 0 & 0 & 0 & 1 & 0 & 1 & 23 \\
\hline & $27,91 \%$ & $16,67 \%$ & $4,17 \%$ & $15,79 \%$ & $0,00 \%$ & $0,00 \%$ & $0,00 \%$ & $3,45 \%$ & $0,00 \%$ & $14,29 \%$ & $10,85 \%$ \\
\hline \multirow[t]{2}{*}{ Oportunidade Perdida } & 0 & 1 & 1 & 0 & 0 & 1 & 0 & 0 & 2 & 1 & 6 \\
\hline & $0,00 \%$ & $3,33 \%$ & $4,17 \%$ & $0,00 \%$ & $0,00 \%$ & $20,00 \%$ & $0,00 \%$ & $0,00 \%$ & $16,67 \%$ & $14,29 \%$ & $2,83 \%$ \\
\hline TOTAL & 43 & 30 & 24 & 19 & 23 & 5 & 20 & 29 & 12 & 7 & 212 \\
\hline \multicolumn{12}{|c|}{ CHINA } \\
\hline Matriz & PP & RB1 & RB2 & LT1 & LT2 & MT1 & MT2 & MT3 & AT1 & AT2 & TOTAL \\
\hline \multirow[t]{2}{*}{ Ótimo } & 4 & 4 & 9 & 5 & 9 & 2 & 11 & 15 & 9 & 3 & 71 \\
\hline & $9,30 \%$ & $13,33 \%$ & $37,50 \%$ & $26,32 \%$ & $39,13 \%$ & $40,00 \%$ & $55,00 \%$ & $51,72 \%$ & $75,00 \%$ & $42,86 \%$ & $33,49 \%$ \\
\hline \multirow[t]{2}{*}{ Em declínio } & 29 & 20 & 12 & 14 & 14 & 3 & 8 & 14 & 3 & 3 & 120 \\
\hline & $67,44 \%$ & $66,67 \%$ & $50,00 \%$ & $73,68 \%$ & $60,87 \%$ & $60,00 \%$ & $40,00 \%$ & $48,28 \%$ & $25,00 \%$ & $42,86 \%$ & $56,60 \%$ \\
\hline \multirow[t]{2}{*}{ Retrocesso } & 10 & 5 & 1 & 0 & 0 & 0 & 1 & 0 & 0 & 0 & 17 \\
\hline & $23,26 \%$ & $16,67 \%$ & $4,17 \%$ & $0,00 \%$ & $0,00 \%$ & $0,00 \%$ & $5,00 \%$ & $0,00 \%$ & $0,00 \%$ & $0,00 \%$ & $8,02 \%$ \\
\hline \multirow[t]{2}{*}{ Oportunidade Perdida } & 0 & 1 & 2 & 0 & 0 & 0 & 0 & 0 & 0 & 1 & 4 \\
\hline & $0,00 \%$ & $3,33 \%$ & $8,33 \%$ & $0,00 \%$ & $0,00 \%$ & $0,00 \%$ & $0,00 \%$ & $0,00 \%$ & $0,00 \%$ & $14,29 \%$ & $1,89 \%$ \\
\hline TOTAL & 43 & 30 & 24 & 19 & 23 & 5 & 20 & 29 & 12 & 7 & 212 \\
\hline \multicolumn{12}{|c|}{ ÁFRICA DO SUL** } \\
\hline Matriz & PP & RB1 & RB2 & LT1 & LT2 & MT1 & MT2 & MT3 & AT1 & AT2 & TOTAL \\
\hline \multirow[t]{2}{*}{ Ótimo } & 1 & 3 & 2 & 7 & 3 & 2 & 7 & 11 & 5 & 0 & 41 \\
\hline & $2,33 \%$ & $10,34 \%$ & $8,33 \%$ & $36,84 \%$ & $13,04 \%$ & $40,00 \%$ & $35,00 \%$ & $37,93 \%$ & $41,67 \%$ & $0,00 \%$ & $19,43 \%$ \\
\hline \multirow[t]{2}{*}{ Em declínio } & 14 & 11 & 8 & 2 & 5 & 2 & 5 & 9 & 3 & 0 & 59 \\
\hline & $32,56 \%$ & $37,93 \%$ & $33,33 \%$ & $10,53 \%$ & $21,74 \%$ & $40,00 \%$ & $25,00 \%$ & $31,03 \%$ & $25,00 \%$ & $0,00 \%$ & $27,96 \%$ \\
\hline Retrocesso & 27 & 10 & 10 & 6 & 7 & 0 & 6 & 6 & 0 & 2 & 74 \\
\hline & $62,79 \%$ & $34,48 \%$ & $41,67 \%$ & $31,58 \%$ & $30,43 \%$ & $0,00 \%$ & $30,00 \%$ & $20,69 \%$ & $0,00 \%$ & $28,57 \%$ & $35,07 \%$ \\
\hline Oportunidade Perdida & 1 & 5 & 4 & 4 & 8 & 1 & 2 & 3 & 4 & 5 & 37 \\
\hline & $2,33 \%$ & $17,24 \%$ & $16,67 \%$ & $21,05 \%$ & $34,78 \%$ & $20,00 \%$ & $10,00 \%$ & $10,34 \%$ & $33,33 \%$ & $71,43 \%$ & $17,54 \%$ \\
\hline TOTAL & 43 & 29 & 24 & 19 & 23 & 5 & 20 & 29 & 12 & 7 & 211 \\
\hline
\end{tabular}

Fonte: Elaboração própria a partir de dados do Tradecan2009

Notas: Os percentuais correspondem ao total indicado na última linha de cada país.

* Para a Rússia a matriz de competitividade corresponde ao período 1991/2007.

** Para a África do Sul a matriz de competitividade corresponde ao período 1985/2000.

A análise keynesiana proporciona uma categorização dos BRICS diferente da evidenciada na análise schumpeteriana. Nesse contexto, Índia e China se sobressaem com grande superioridade em relação aos outros países do grupo, exibindo alta competitividade em todos os setores, mas com 
especial ênfase nos grupos mais intensivos em tecnologia. A grande diferença entre os dois países se dá no market share, visualizado na perspectiva schumpeteriana, que evidenciam a superioridade absoluta dos ganhos da China, uma vez que sua parcela de mercado é substancialmente maior. Já Brasil, Rússia e África do Sul se unem em outro grupo, que ainda demonstram deficiências nesse contexto de competitividade internacional, sobretudo no que tange aos setores mais intensivos em tecnologia, com o Brasil apresentando dados um pouco mais favoráveis e a África do Sul com os piores números.

Após a análise sob as duas perspectivas, é possível constatar que ambas estão intimamente relacionadas, pois o perfil tecnológico influencia a demanda, uma vez que, mesmo com o boom de commodities vivido dentro período, a maioria dos setores que obtiveram aumento na demanda internacional são os que possuem maior conteúdo tecnológico. Por isso, para que o conjunto dos BRICS possa ser de fato considerado uma futura potência mundial, ao menos dentro do comércio internacional, é necessária uma mudança no perfil tecnológico, a despeito das vantagens comparativas demonstradas por cada país.

\subsection{Contribuição ao saldo}

O índice de contribuição ao saldo mostra quais setores contribuem positivamente para a balança comercial do país e, portanto, nesse caso ajuda a verificar qual o nível de maturidade do processo de mudança estrutural, uma vez que os setores mais importantes e consolidados devem apresentar resultados positivos.

No caso do Brasil, o indicador corrobora os resultados expostos anteriormente, uma vez que produtos agrícolas e alimentos são os setores que apresentaram grande destaque na contribuição para o saldo positivo da balança comercial no ano de 2007. Combustíveis e produtos de mineração, aço e ferro, produtos automotivos e vestuário também contribuem positivamente. Todos os outros setores apresentam saldos negativos, confirmando que o crescimento apresentado pelos setores de maior tecnologia sob a perspectiva schumpeteriana é ínfimo e não consegue contribuir para o saldo comercial, ao contrário, mostraram resultados ainda são piores que os de 1990, além disso, a perda de competitividade dos setores de baixa tecnologia pode ser observada pela contribuição negativa de manufaturas e têxteis em 2007, mas que obtiveram saldo positivo em 1990. Os resultados ratificam o processo de especialização do país em produtos primários e, por consequência, o processo de deterioração da sua pauta de exportações para a manutenção do superávit na balança comercial.

Mais uma vez, o processo de especialização e de forte dependência se manifesta com muito mais intensidade na Rússia. Os setores de produtos agrícolas, manufaturas, químicos, circuitos 
integrados e componentes eletrônicos, produtos automotivos e vestuário que apresentavam contribuição ao saldo positiva passaram a contribuir negativamente para a balança, somente aço e ferro se manteve positivo, aumentando ainda mais a importância dos setores de combustíveis para a manutenção do saldo positivo da balança comercial. Esse caso também é muito preocupante, visto que é recurso escasso na natureza e possui preço de mercado relativamente volátil, deixando, portanto, a Economia do país muito vulnerável.

Os índices de contribuição ao saldo da Índia evidenciam o fato de o país estar longe de um patamar produtivo e de comércio internacional adequado, mesmo com os bons resultados da matriz de competitividade e do início de um processo de mudança estrutural, são os setores de produtos agrícolas, alimentos, têxteis e vestuário que contribuem positivamente para a balança comercial, durante o período analisado somente os produtos automotivos obtiveram uma reversão e em 2007 apresentaram saldo positivo. Vale salientar também que o país apresentou déficit na balança comercial, o que demonstra que o avanço obtido não foi capaz de suprir sua dependência externa.

Tabela $10^{10}$ : Índice de contribuição ao saldo

\begin{tabular}{|c|c|c|c|c|c|}
\hline \multicolumn{6}{|c|}{ Ano 1} \\
\hline Setor & Brasil & Rússia & Índia & China & A. do Sul \\
\hline Produtos Agrícolas & 15,35 & 0,09 & 5,46 & 6,18 & 12,19 \\
\hline Alimentos & 14,25 & $-11,23$ & 6,16 & 9,10 & 7,36 \\
\hline Combustíveis e Produtos de Mineração & $-4,69$ & 252,48 & $-21,06$ & 10,47 & 6,98 \\
\hline Combustíveis & $-11,61$ & 195,84 & $-18,29$ & 10,81 & $-8,74$ \\
\hline Manufaturados & 7,61 & 28,04 & 1,08 & 5,40 & $-32,13$ \\
\hline Aço e Ferro & 7,10 & 23,55 & $-2,74$ & $-4,40$ & 18,32 \\
\hline Químicos & $-3,45$ & 12,76 & $-5,35$ & $-8,21$ & $-8,11$ \\
\hline Farmacêuticos & $-0,63$ & $-4,39$ & 0,60 & 0,63 & $-4,20$ \\
\hline Máquinas e Equipamento de Transporte & $-1,16$ & $-10,80$ & $-8,75$ & $-29,92$ & $-39,66$ \\
\hline Equip. de Telecomunicação e Escritório & $-1,78$ & $-3,47$ & $-1,47$ & $-2,61$ & $-22,24$ \\
\hline Equip. de Pro. de Dados e Escritório & $-0,64$ & $-0,80$ & $-0,38$ & $-1,11$ & $-8,00$ \\
\hline Equipamentos de Telecomunicação & $-0,25$ & $-2,77$ & $-0,44$ & 0,24 & $-12,16$ \\
\hline Circuitos Int. e Comp. Eletrônicos & $-0,89$ & 0,11 & $-0,65$ & $-1,73$ & $-2,07$ \\
\hline Produtos Automotivos & 3,25 & 0,34 & $-0,19$ & $-4,31$ & 1,90 \\
\hline Têxteis & 1,12 & $-0,92$ & 5,94 & 5,40 & $-2,50$ \\
\hline Vestuário & 0,41 & 0,93 & 7,74 & 26,95 & $-0,03$ \\
\hline \multicolumn{6}{|c|}{2007} \\
\hline Setor & Brasil & Rússia & Índia & China & A. do Sul \\
\hline Produtos Agrícolas & 30,03 & $-2,67$ & 4,55 & $-7,59$ & 2,40 \\
\hline Alimentos & 26,77 & $-9,78$ & 5,26 & 0,21 & 0,30 \\
\hline Combustíveis e Produtos de Mineração & 2,95 & 188,66 & $-41,94$ & $-48,07$ & 28,17 \\
\hline Combustíveis & $-6,61$ & 166,10 & $-40,05$ & $-24,11$ & $-28,26$ \\
\hline Manufaturados & $-1,62$ & $-63,19$ & $-6,82$ & 131,26 & $-67,12$ \\
\hline Aço e Ferro & 5,67 & 11,84 & $-0,06$ & 7,84 & 20,57 \\
\hline Químicos & $-8,96$ & $-1,35$ & $-3,45$ & $-13,47$ & $-9,87$ \\
\hline Farmacêuticos & $-2,34$ & $-4,98$ & 2,31 & 0,60 & $-4,87$ \\
\hline Máquinas e Equipamento de Transporte & $-0,22$ & $-59,47$ & $-25,36$ & 47,27 & $-57,25$ \\
\hline Equip. de Telecomunicação e Escritório & $-7,09$ & $-12,81$ & $-11,39$ & 34,74 & $-22,72$ \\
\hline Equip. de Pro. de Dados e Escritório & $-2,30$ & $-3,93$ & $-3,04$ & 34,47 & $-9,96$ \\
\hline
\end{tabular}

\footnotetext{
${ }^{10}$ Para o cálculo do indicador eram necessários dados de todos os setores dentro de um mesmo ano, o que se obteve somente a partir de 1990 para Brasil, Índia e China e 2000 para Rússia e África do Sul.
} 


\begin{tabular}{|c|c|c|c|c|c|}
\hline Equipamentos de Telecomunicação & $-2,08$ & $-8,55$ & $-7,54$ & 31,64 & $-11,63$ \\
\hline Circuitos Int. e Comp. Eletrônicos & $-2,70$ & $-0,33$ & $-0,81$ & $-31,37$ & $-1,13$ \\
\hline Produtos Automotivos & 3,51 & $-22,46$ & 0,99 & $-0,29$ & $-8,13$ \\
\hline Têxteis & $-0,55$ & $-1,43$ & 6,04 & 11,27 & $-2,39$ \\
\hline Vestuário & $-0,24$ & $-2,33$ & 7,91 & 32,50 & $-3,06$ \\
\hline \multicolumn{6}{|c|}{2012} \\
\hline Setor & Brasil & Rússia & Índia & China & A. do Sul \\
\hline Produtos Agrícolas & 32,55 & $-5,15$ & 9,00 & $-11,02$ & 2,38 \\
\hline Alimentos & 29,56 & $-8,60$ & 6,92 & $-4,17$ & 0,21 \\
\hline Combustíveis e Produtos de Mineração & 8,37 & 182,81 & $-78,51$ & $-58,06$ & 23,96 \\
\hline Combustíveis & $-6,09$ & 170,28 & $-70,64$ & $-34,28$ & $-33,96$ \\
\hline Manufaturados & $-36,08$ & $-74,16$ & $-4,41$ & 105,28 & $-72,06$ \\
\hline Aço e Ferro & 2,73 & 9,57 & $-0,03$ & 3,77 & 11,89 \\
\hline Químicos & $-12,05$ & $-2,51$ & $-5,38$ & $-7,91$ & $-11,15$ \\
\hline Farmacêuticos & $-2,68$ & $-6,29$ & 4,19 & $-0,24$ & $-5,85$ \\
\hline Máquinas e Equipamento de Transporte & $-21,07$ & $-60,01$ & $-21,13$ & 37,91 & $-49,08$ \\
\hline Equip. de Telecomunicação e Escritório & $-8,29$ & $-10,75$ & $-10,61$ & 23,46 & $-19,03$ \\
\hline Equip. de Pro. de Dados e Escritório & $-2,48$ & $-3,99$ & $-3,71$ & 19,93 & $-8,12$ \\
\hline Equipamentos de Telecomunicação & $-3,70$ & $-6,50$ & $-4,97$ & 20,26 & $-10,05$ \\
\hline Circuitos Int. e Comp. Eletrônicos & $-2,12$ & $-0,27$ & $-1,92$ & $-16,73$ & $-0,86$ \\
\hline Produtos Automotivos & $-3,84$ & $-19,63$ & 2,24 & $-3,75$ & $-3,11$ \\
\hline Têxteis & $-1,47$ & $-1,99$ & 6,43 & 9,19 & $-2,87$ \\
\hline Vestuário & $-1,06$ & $-4,40$ & 7,23 & 18,85 & $-3,83$ \\
\hline
\end{tabular}

Fonte: Elaboração própria a partir de dados da Organização Mundial do Comércio

Algumas reversões ocorridas na China durante o período caracterizam o processo de mudança da estrutura produtiva vivido pelo país durante o período em análise. A contribuição negativa dos setores de produtos agrícolas, combustíveis e combustíveis e produtos de mineração, bem como a forte redução da contribuição dos alimentos, demonstram não só a diminuição da importância desses setores como também o forte crescimento da sua demanda em decorrência dos investimentos feitos. Por outro lado, setores como os de aço e ferro, máquinas e equipamentos de transporte, processamento de dados eletrônicos e equipamentos de escritório passaram a contribuir positivamente e a contribuição dos equipamentos de telecomunicação cresceu bastante. Essa mudança no perfil da balança comercial do país, assim como os demais indicadores analisados, mostra a crescente importância de setores mais intensivos em tecnologia na pauta de exportações da China, vale salientar também que os setores têxteis e de vestuário, não perderam a relevância que possuíam em 1990.

Na África do Sul, assim como nos demais países, com exceção da China, não são grandes as mudanças na contribuição ao saldo da balança comercial. Além do fato de somente setores de menor intensidade tecnológica possuírem saldo positivo, a África do Sul apresenta o mesmo problema da Rússia e depende de setores baseados em recursos escassos da natureza e de preços voláteis, nesse caso, combustíveis e produtos de mineração e aço e ferro, como também a falha da Índia, pois apresenta dependência produtiva e suas exportações não foram capazes de garantir superávit na balança comercial. 
Como ressaltado anteriormente, as modificações ocorridas durante o período de menor intensidade na atividade econômica mundial não foram capazes de modificar a estrutura dos países dos BRICS, como pode ser identificado nos dados de 2012 da Tabela 10, que apresentaram poucas mudanças. Alguns pontos que podem ser destacados são a reversão negativa de Produtos Automotivos e o forte aumento da contribuição negativa de Manufaturados e de Máquinas e Equipamento de Transporte no Brasil, evidenciando ainda mais a queda de desempenho do país nesse período. É possível destacar também a reversão negativa de Alimentos e Farmacêuticos na China, no entanto, estes setores já apresentavam uma muito pequena em 2007.

\section{Considerações Finais}

No que se refere às dotações produtivas, uma das principais forças dos BRICS decorre do fato de o grupo ser relativamente autossuficiente, uma vez que as especializações produtivas dos países em conjunto abrangem setores de todos os níveis tecnológicos. Por essa perspectiva, se o grupo fosse fechado, o Brasil atuaria como fornecedor de produtos agrícolas e de minério de ferro, a Rússia como fornecedora de petróleo e derivados, a Índia como produtora de manufaturas intensivas em trabalho, a China seria fabricante, além dos produtos intensivos em trabalho, dos produtos intensivos em tecnologia e a África do Sul fornecedora de minérios em geral. No entanto, essa configuração aponta que o grupo sofre, em menor escala, da mesma hierarquia produtiva mundial condenada pelas teorias alternativas do comércio internacional, mostrando outra importante diferença interna, além das geográficas, políticas e sociais, como já foi abordado, o que dificulta ainda mais o já difícil processo de integração desses países.

Essa disparidade é refletida no desempenho das exportações para a Economia interna, bem como na importância de cada país no cenário do comércio internacional. Nesse sentido, somente a China pode ser considerada uma candidata a nova potência da Economia mundial, pois sua evolução durante o período se deu de forma coerente com as abordagens keynesiana e schumpeteriana, tanto em conteúdo como em volume. Já Brasil, Rússia, Índia e África do Sul ainda estão longe dos padrões produtivos das economias consideradas hegemônicas, visto que não conseguiram mudar suas estruturas produtivas e continuam fortemente atreladas ao princípio das vantagens comparativas, que não atendem às perspectivas de competitividade tecnológica e de demanda.

Ainda que o Brasil tenha apresentado bons indicadores de comércio internacional em alguns setores mais intensivos em tecnologia e a Índia possua boas perspectivas no que tange à competitividade de demanda, assim como a retomada de uma melhor perspectiva de Rússia e África do Sul no período pós-crise, esses aspectos positivos não representaram contribuição positiva para a 
balança comercial, evidenciando que as cadeias produtivas desses setores não são internamente completas e continuam dependentes das importações.

Sendo assim, os aspectos produtivos dos BRICS não podem ser considerados como um fator que, de alguma forma, una os países ou que possa alavancar o grupo ao patamar de nova potência da Economia mundial ou concorrente do G-6 como pretendiam O’Neill (2001) e Wilson e Purushothaman (2003), ao contrário, esses fatores só tornam o grupo mais vulnerável aos interesses de empresários e especuladores estrangeiros, como apontaram Wilson e Purushothaman (2003) e Kregel (2009).

\section{Referências}

ABNT Associação Brasileira de Normas Técnicas. NBR 14.724, de 17.03.2011. Informação e documentação, trabalhos acadêmicos, apresentação. Válida a partir de 17.04.2011. Rio de Janeiro, 2011.

BAUMANN, R.; ARAÚJO, R.; FERREIRA, J. As Relações Comerciais do Brasil com os demais BRICs. In: BAUMANN, R. (Org.). O Brasil e os demais BRICs - Comércio e Política. Brasília, DF: CEPAL. Escritório no Brasil/IPEA, 2010. p. 9-46.

DE GAUT, M. A ilusão dos BRICS. abr. 2013. Disponível em: <http://relacoesinternacionais.com.br/Economia-internacional/ilusao-brics/>

DE VIZIA, B.; COSTA, G. O tempo do BRIC. Desafios do Desenvolvimento, Brasília, DF, ano 7, n. 60, p. 30-37, mar./abr. 2010.

DOSI, G.; PAVITT, K.; SOETE, L. L. The economics of technological change and international trade. Brighton, Wheatshaf, 1990.

FAGERBERG, J.; VERSPAGEN, B. Innovation, grouth, and economic development: have the conditions for catch up changed? International Journal of Technological Learning, Innovation and Development, v. 1, n. 1, 2007.

GURRIERI, A. La obra de Prebisch en la CEPAL. v. 1. Mexico: Fondo de cultura econômica, 1982.

HAUSMMAN, R.; HWANG, J.; RODRICK, D. What you export matters. NBER Working Paper Series No. 1905, 2005.

INSTITUTO DE PESQUISA ECONÔMICA APLICADA - IPEA. Relações comerciais e de investimentos do Brasil com os demais países do BRICS. Comunicados do Ipea, n. 86, 13 abr. 2011. Disponível em:

<http://www.ipea.gov.br/portal/images/stories/PDFs/comunicado/110413_comunicadoipea86.pdf>. . Rússia, Índia e China: comércio exterior e investimento direto externo. Comunicados do Ipea, n. 43, 14 abr. 2010. Disponível em:

<http://www.ipea.gov.br/portal/images/stories/PDFs/comunicado/100413_comunicadoipea43.pdf>.

KREGEL, J. A crise global e as implicações para os países emergentes: o B dos BRICs se justifica? In: VELlOSO, J. P. dos R. (Org.). A crise global e o novo papel dos BRICs. Rio de Janeiro: José Olympio, 2009. 
LALL, S.; ALBALADEJO, M. Indicators of the relative importance of IPRs in developing countries. Geneva: UNCTAD, 2001. Disponível em: <http://www.ictsd.org/unctad-ictsd/>.

LAPLANE, M. F.; SARTI, F.; HIRATUKA, C.; SABBATINI, R. C. O caso brasileiro. In: CHUDNOVSKY, D. (Coord.). El boom de las inversiones extranjeras directas em El Mercosur. Buenos Aires: Siglo XXI, 2001.

LAURSEN, K. MELICIANI, V. The importance of technology-based intersectorial linkages for market share dynamics, Review of World Economics, v. 136, n. 4, 2002, p. 702-723.

MCCOMBIE, J.S.L.; THIRWALL, A.P. Economic growth and the balance-of-payments constraint. Basingstoke: Macmillan, 1994.

MADENG, O. International competitiveness and specialization. CEPAL Review, n. 45, 1991. p. 25-40.

MALERBA, F.; MONTOBBIO, F. Exploring factors affecting international technological specialization: the role of knowledge flows and the structure on innovative activity. Journal of Evolutionary Economics, v. 13, n. 4, 2003, p. 411-434. crossref http://dx.doi.org/10.1007/s00191003-0162-z

MINISTÉRIO DAS RELAÇÕES EXTERIORES. BRICS: Brasil, Rússia, Índia, China e África do Sul. 2013. Disponível em: < http://www.itamaraty.gov.br/temas/mecanismos-interregionais/agrupamento-brics $>$

Comércio exterior dos BRICS. ago. 2012. Disponível em:

<http://www.brasilglobalnet.gov.br/ARQUIVOS/IndicadoresEconomicos/ComExtBRICs.pdf.

O’NEILL, J. Building Better Global Economics BRICs. Global Economics Paper, n. 66, 30 nov. 2001. Disponível em: <http://www.goldmansachs.com/our-thinking/topics/brics/brics-reportspdfs/build-better-brics.pdf $>$.

PARENTE, S.; PRESCOTT, E. A unified theory of the evolution of international income levels. Research Department Staff Report 333, Federal Reserve Bank of Minneapolis 2004.

PAVITT, K. Sectoral patterns of technical change: towards and taxonomy and a theory. Research Policy, v. 13, 1984.

PREBISCH, R. O desenvolvimento econômico da América Latina e alguns de seus problemas principais. In: BIELSCHOWSKY, R. (Org.). Cinquenta anos de pensamento na CEPAL. v. 1. Rio de Janeiro: Record, 2000.

SCHMIDT FILHO, R. Uma perspectiva schumpeteriana/estruturalista do padrão de competitividade internacional brasileiro: 1985-2007. 2011. 239 f. Tese (Doutorado em Desenvolvimento Econômico) - Setor de Ciências Sociais Aplicada, Universidade Federal do Paraná, Curitiba, 2011.

THIRLWALL, A. P. The balance of payments constraints as an explanation of international grouth rate diferences, Banca Nazionale del Lavoro Quartely Review, march, 1979.

WILSON, D.; PURUSHOTHAMAN, R. Dreaming With BRICs: The Path to 2050. Global Economics Paper, n. 99, 1 out. 2003. Disponível em: <http://www.goldmansachs.com/ourthinking/topics/brics/brics-reports-pdfs/brics-dream.pdf $>$.

XAVIER, C. L. Padrões de especialização e competitividade no exterior brasileiro. Tese (Doutorado em Economia) - UNICAMP, Campinas, 2000. 
ZUCOLOTO, G. F.; CASSIOLATO, J. E. How globalized are R\&D activities: some evidence from BRICS countries. IE-UFRJ, 2007. Disponível em:

<http://brics.redesist.ie.ufrj.br/textos_count.php?cod=628>.

Recebido em 18.12.13

Aprovado em 03.07.14 